\title{
Optimal Nonlinear Income Taxation with a Finite Population
}

\author{
Jonathan Hamilton \\ and \\ Steven Slutsky \\ Department of Economics \\ Warrington College of Business Administration \\ University of Florida \\ Gainesville FL 32611-7140 USA
}

April 2003

A preliminary version of this paper was presented at the Southern Economic Association Meetings and the Association for Public Economic Theory Meeting. We thank Michael Blake, Richard Romano, David Sappington, and Art Snow for comments. We thank the Warrington College of Business Administration for financial support for this research. All errors are solely our responsibility. 


\begin{abstract}
In the optimal nonlinear income taxation problem of Mirrlees and Stiglitz, the government's tax schedules guarantee consumption-income bundles for each type of consumer regardless of others' actions. Piketty (Journal of Economic Theory, 1993) allows tax schedules to depend on other consumers' actions. When the government knows the exact distribution of abilities, it can construct more complicated tax schedules which can implement any first-best allocation as the unique outcome of the individuals' revelation game, in contrast to the secondbest properties of conventional tax schedules. Piketty's mechanism may assign suboptimal or even infeasible allocations to consumers when the distribution of individual reports of types differs from the true distribution of types which the government knows.

We consider the effect of requiring either that tax schedules must balance the government budget for every possible vector of revelation by individuals or that after individuals have revealed their types, the government can change its initially announced values subject to constraints that no one who revealed truthfully can be made worse off. Depending on whether individuals reveal their type by simple announcements or by committing to an action, the results differ from those in Mirrlees-Stiglitz and Piketty.
\end{abstract}




\section{Introduction}

Since Mirrlees's [1971] classic article, optimal income taxation has been examined from many different perspectives. Almost all subsequent literature incorporates Mirrlees's essential insight that the government cannot perfectly identify individuals' types and assess personalized lump-sum taxes. As a consequence, tax schedules must satisfy incentive compatibility (or selfselection) constraints. Once the government announces tax schedules, these constraints are formulated so that an individual's tax payments do not depend on the behavior of others. Even though one might think that there could be benefits from incorporating interdependencies across taxpayers, Hammond [1979] demonstrates that in a continuum model the social planner cannot improve on this solution by using knowledge of the precise distribution of types in the economy. Stiglitz [1982] and others have modified the continuum assumption by modeling the economy as consisting of a finite number of different types, but continuing to assume there is a large (infinite) number of individuals of each type. Most papers modeling a finite number of types retain the Mirrlees approach in which the consumption bundles assigned to individuals depend only on their own choices.

When there is a finite population of consumers (not just types), researchers in public economics have long known, at least informally, that it is possible to improve on the optimal allocations found in the Mirrlees-Stiglitz approach. Suppose the government knew precisely the number of people of each type. The government could announce that, when the set of reports of types it received did not match the true distribution, then all taxpayers would be executed. One equilibrium of such a mechanism would be truthful reporting of types by all individuals even if the resulting consumption bundles violate self-selection constraints. Many researchers dismiss this possibility for a number of reasons. First, it supports multiple equilibria. Due to the extreme 
nature of the punishment, any set of announcements which matches the true distribution in aggregate numbers is a Nash equilibrium, even if some individuals misreport their types.

Starting from any such pattern with some misrevelation, no one who is falsely revealing her type would be willing to deviate by telling the truth since this would trigger the harsh penalty. Hence, while truthful revelation is a Nash equilibrium, a situation in which an equal number of more able and less able individuals misreveal their types is also a Nash equilibrium.

A second objection is that the planner, whether a Bergson-Samuelson social welfare maximizer or a revenue-maximizing Leviathan, after obtaining announcements that it knows to be false in the aggregate can do better than to impose the penalties. Suppose everyone reports her true type, except that one high-ability person reports as having low ability. In the scheme above, to punish the deviator, the planner must also punish all others who report low ability (and truly have low ability), reducing social welfare or government revenue. Consequently, individuals may not view the planner's threats to impose the death penalty as credible in such circumstances.

In an important and provocative paper, Piketty [1993] shows that, with a finite population, a social planner can design a mechanism whose unique Nash equilibrium implements undistorted allocations, even those which violate the Stiglitz self-selection constraints. Piketty thus shows that the first objection of a multiplicity of Nash equilibria is not really valid. If the punishments are not too large, then the unique Nash equilibrium is for everyone to reveal truthfully. Piketty establishes uniqueness by constructing a mechanism whose equilibrium is dominance-solvable (it can be found by sequential elimination of strictly dominated strategies). He does not consider the second objection—off the equilibrium path, he assumes individuals believe that the government will carry out whatever policies it has announced. Although one 
might argue that the punishments are more credible by virtue of being smaller, they are still not optimizing behavior for a planner who reaches a state in which some individuals have lied about their types. Indeed, off the equilibrium path, the outcome announced in the event that some people lie may not even balance the budget, and thus may not be feasible.

We tighten Piketty's analysis by imposing further conditions on the off-equilibrium path allocations announced by the government which are to be implemented if some individuals were to misreveal their types. Restrictions on such off-equilibrium outcomes can affect whether the government is able to sustain an undistorted (first-best) allocation in which all individuals report truthfully. In imposing such restrictions, the issue is what flexibility may exist in modifying allocations after there is untruthful revelation by some individuals. We consider three possible restrictions. The first (and weakest) requirement is that the announced government plan must be feasible in all possible circumstances, whether or not they arise after truthful or untruthful revelation. This prevents the government from running a deficit on or off the equilibrium path. The second (which is closely related) requires budget balance in all allocations. This tightens the first requirement by preventing the government from generating a surplus off the equilibrium path. It is not obvious how the government could use surplus resources without affecting revelation incentives. Simply throwing away the excess would seem to generate questions of credibility quite easily. $^{1}$

The third restriction is to impose some type of optimality on the allocations on and off the equilibrium path. One way of viewing these restrictions is that the planner makes initial announcements of its policy before individuals reveal their type. If only feasibility or budget balance are imposed, the assumption is that the planner can wait to enact its announcements but the announcements are constrained not to run a deficit or to balance the budget exactly in all 
situations. If the off-equilibrium policies must also satisfy some optimality restriction, then the assumption is that the planner cannot completely commit to carry out its announced policies. At the time at which it must enact them, it would not carry out anything announced if it could do better.

Modeling optimization by the planner after the initial choice of what tax schedules to announce is not straightforward. Some constraints are needed on how the policies can change. If the planner can reoptimize at points off the equilibrium path after hearing individuals announce their types, why can't the planner reoptimize on the equilibrium path? After learning individuals' types from their announcements, why can't the planner impose different lump-sum taxes on each type? If the punishments off the equilibrium path are not credible because they are not optimal to enforce given the information available to the planner, on the equilibrium path the planner must have a similar opportunity to update his choice of the tax schedule. This would imply that the planner will offer undistorted bundles after learning individuals' types. ${ }^{2}$

Our approach is to assume that the government makes a partial commitment in announcing its policies. In any state of the world, the planner can replace its announced allocation with one which would be Pareto superior under the assumption that individuals' announcements were truthful. In other words, the government commits not to harm any individuals after they announce their types, based upon the preferences of the type that individual claims to be. The government can revise its allocation for a type of consumers as long as that type is not made worse off, although individuals who had falsely reported that they were that type may be made worse off by such revisions. The essential point is that the government is limited in its ability to use information it acquires about an individual's type in order to redistribute more resources from that type to other groups. One possible justification for this assumption is that an 
initial announcement by the government gives individuals an entitlement which they can enforce in court if the government were to change its policy and reduce their welfare. ${ }^{3}$

The question of what are the appropriate restrictions to place on the planner's policies off the equilibrium path arises more generally than in the optimal taxation problem. It is significant in any mechanism design problem, but it has not yet been adequately studied. Almost all restrictions imposed on mechanisms apply only on the equilibrium path. Restrictions on the mechanism off-the-equilibrium path are not unimportant because they arise with zero probability. ${ }^{4}$ What individuals believe will happen in such situations can be crucial in defining equilibrium actions. In effect, incorporating optimization by the planner after initial announcements subject to some commitment restrictions means the mechanism design problem no longer has the planner standing outside the game setting the rules under which individuals will play. The planner is now another player in the game, able to make certain moves but subject to the standard type of restrictions on equilibrium behavior.

When considering off-the-equilibrium-path behavior, additional issues arise that are not present in the Mirrlees-Stiglitz context. What actions are individuals committed to if others' behavior moves the game off the equilibrium path? The standard analysis, following the revelation principle, has each individual directly announcing her own type, without needing to take any particular action to do so. Thus, the planner, at each of its information sets on or off the equilibrium path, can assign any bundle it desires to an individual. There are no restrictions linking bundles given to an individual at different information sets. We will call this approach announcement revelation.

Alternatively, individuals may reveal their types by taking an action, such as determining how many hours to work. Even if others misreveal and move the game off the equilibrium path, 
the planner cannot adjust the bundles to change individuals' work decisions. After revelation, the planner can only alter the other components of the consumption bundles. This approach, which we call action revelation, is the one Piketty [1993] uses.

One can justify either approach, depending on circumstances. In one sense, announcement revelation is more general since the planner could act as if the action revelation restrictions were binding, even if individuals announced types to the planner at the start of the game before taking any other actions. However, if the planner is free to reoptimize as discussed above, then such behavior by the planner may be ruled out. Action revelation seems more descriptive of actual income tax systems where individuals report income at the end of a tax year after earning the income. The government can only adjust consumption (or saving) in response to misrevelation. Given the differences in the approaches and their applicability, we present results for each of them below.

Section 2 introduces the basic model of the economy in which the planner wants to undertake redistribution. We present the Stiglitz problem and the Piketty problem as benchmarks for our further discussion. We describe the problems that can exist with respect to off-theequilibrium-path allocations in the Piketty approach. In Section 3, we analyze the impact of imposing budget balance restriction off the equilibrium path. In Section 4, we consider the effect of imposing partial commitment restrictions. Section 5 contains our conclusions.

\section{The Model}

Stiglitz [1982] formulated the standard optimal nonlinear income tax model for discrete types. Brito et al. [1990] present a general version of this model. Assume that there is a continuum of individuals consisting of only two types, with the mass of each type equal to $\mathrm{n}^{\mathrm{i}}$. Let $n$ denote the total population, where $n=n^{1}+n^{2}$. Each individual of type $i, i=1,2$, has a 
utility function $\mathrm{U}^{\mathrm{i}}\left(\mathrm{X}^{\mathrm{i}}\right)$ which is continuous and quasiconcave. The vector $\mathrm{X}^{\mathrm{i}}$ is a net trade bundle with two components, the first being labor income and the second consumption. The utility functions can differ across types because of taste, productivity, or endowment differences. We assume single crossing with the slope of the indifference curves for types 1's through any bundle X steeper than that for type 2's.

Because $\mathrm{X}_{1}^{\mathrm{i}}$ is a bad (effort), the indifference curves have positive slopes with $\mathrm{MRS}^{\mathrm{i}}=-\frac{\partial \mathrm{U}^{\mathrm{i}} / \partial \mathrm{X}_{1}^{\mathrm{i}}}{\partial \mathrm{U}^{\mathrm{i}} / \partial \mathrm{X}_{2}^{\mathrm{i}}}$. For each type, we assume that the marginal utility of consumption goes to infinity as consumption goes to zero. Thus, for any bundle $X$ with $p \cdot X<0$, there is a bundle $\left(0, \hat{X}_{2}\right)$ which is indifferent to it for some $\hat{X}_{2}>0$. In other words, every indifference curve through a bundle $\mathrm{X}^{*}$ below the line $\mathrm{p} \cdot \mathrm{X}=0$ must cross that line at some level of $\mathrm{X}_{1}$ less than $\mathrm{X}_{1}^{*}$. Individuals are also assumed to have a maximum possible labor supply $\overline{\mathrm{L}}$ and thus each type has a maximum possible pre-tax income denoted $\overline{\mathrm{X}}_{1}^{1}$ and $\overline{\mathrm{X}}_{1}^{2}$ where $\overline{\mathrm{X}}_{1}^{1}<\overline{\mathrm{X}}_{1}^{2}$. As $\mathrm{X}_{1}^{\mathrm{i}}$ approaches $\overline{\mathrm{X}}_{1}^{\mathrm{i}}$, the marginal disutility of labor goes to negative infinity. Hence, at any bundle $\mathrm{X}^{*}$ with $\mathrm{p} \cdot \mathrm{X}^{*}<0$, the indifference curve for type $\mathrm{i}$ through $\mathrm{X}^{*}$ must cross the line $\mathrm{p} \cdot \mathrm{X}=$ 0 at some $\mathrm{X}_{1}^{\mathrm{i}}$ between $\mathrm{X}_{1}^{*}$ and $\overline{\mathrm{X}}_{1}^{\mathrm{i}}$. There is a linear production technology specifying feasible pairs of net trades, $p \cdot\left(n^{1} X^{1}+n^{2} X^{2}\right) \leq 0$. Without loss of generality, the units of the commodities can be defined so that $\mathrm{p}=(-1,1)$. A net trade pair for these types involves no redistribution if $\mathrm{p} \cdot \mathrm{X}^{\mathrm{i}}=0$.

The social planner assigns net trade bundles. If the social planner had full information about which individuals were of which type, the full information first-best outcomes would be the solution to: 


$$
\begin{gathered}
\operatorname{Max} \alpha n^{1} U^{1}\left(X^{1}\right)+(1-\alpha) n^{2} U^{2}\left(X^{2}\right) \\
X^{1}, X^{2} \text { s.t. } \quad p \cdot\left(n^{1} X^{1}+n^{2} X^{2}\right) \leq 0 .
\end{gathered}
$$

Choice of the parameter $\alpha$ allows this problem to describe any first-best allocation. ${ }^{5}$ Let $\mathrm{X}^{\mathrm{i}}\left(\mathrm{n}^{1}\right.$, $\alpha$ ) denote the solution to (I) for any $\mathrm{n}^{1}$ and $\alpha$, where the total population $\mathrm{n}$ is fixed.

There exists an $\alpha^{0}$ such that the solution to (I) entails no redistribution $\left(\mathrm{p} \cdot \mathrm{X}^{1}\left(\mathrm{n}^{1}, \alpha^{\mathrm{o}}\right)=\mathrm{p} \cdot \mathrm{X}^{2}\left(\mathrm{n}^{1}, \alpha^{\mathrm{o}}\right)=0\right)$. For $\alpha>\alpha^{0}$, there will be transfers from the type 2's to type 1 's $\left(n^{1} p \cdot X^{1}\left(n^{1}, \alpha\right)=-n^{2} p \cdot X^{2}\left(n^{1}, \alpha\right)>0\right)$ and the reverse for $\alpha<\alpha^{0} .{ }^{6}$

Without full information, the planner knows the utility functions, $\mathrm{U}^{\mathrm{i}}\left(\mathrm{X}^{\mathrm{i}}\right)$, and the masses $\mathrm{n}^{\mathrm{i}}$ of each type, but cannot identify individuals' types. To induce individuals to report truthfully, the planner offers each individual a choice from the same pair of net trade bundles, where each bundle is intended for a particular consumer type and where the bundles must satisfy selfselection or incentive compatibility constraints. The planner's optimization problem then becomes:

$$
\begin{array}{rc}
\underset{X^{1}, X^{2}}{\operatorname{Max}} \alpha n^{1} U^{1}\left(X^{1}\right)+(1-\alpha) n^{2} U^{2}\left(X^{2}\right) \\
\text { s.t. } \quad U^{1}\left(X^{1}\right) \geq U^{1}\left(X^{2}\right) \\
U^{2}\left(X^{2}\right) \geq U^{2}\left(X^{1}\right) \\
p \cdot\left(n^{1} X^{1}+n^{2} X^{2}\right) \leq 0 .
\end{array}
$$

Brito, et al. [1990] show that at most one of these self-selection constraints can be violated at any point on the first-best utility possibility frontier. The taxes for any individual defined from the solution to this problem satisfy the property that they depend only on the individual's actions and not on the actions of others. 
The allocations $\mathrm{X}^{1}$ and $\mathrm{X}^{2}$ solving (II) are the bundles assigned to individuals in equilibrium. In this specification, nothing explicit has been said about allocations if the mass of people who reveal themselves as each type differs from the mass known to be that type by the planner. With a continuum of individuals, this is not an issue because a solution to (II) is a Nash equilibrium since any individual has a mass of zero. Hence, if one individual misreveals, the planner will not observe this, either directly or through any resulting budget imbalance. With a finite number of individuals as well as types, this will not be true. Even if only one individual misreveals her type, the planner at some stage of the game will detect that the revealed pattern of revelation does not accord with what it knows for certain to be the actual pattern. If the net trade bundles of the two types use different resources $\left(p \cdot X^{1} \neq p \cdot X^{2}\right)$, misrevelation causes either a surplus or a deficit. Since the planner will detect misrevelation by even one individual, it can condition the bundles offered to each type on what others reveal (this conditioning must be anonymous in the sense that it only depends on the aggregate announcements of others). In fact, if a deficit results, the planner not only can but must alter taxes to maintain feasibility.

Piketty developed a formalization of this problem for a finite population. Let $\mathrm{N}^{1}$ be the number who reveal themselves as type 1 and for any $0 \leq N^{1} \leq n^{1}+n^{2}$, let $\left(X^{1}\left(N^{1}\right), X^{2}\left(N^{1}\right)\right)$ be the bundles assigned to the two types. The appropriate self-selection constraints in the game with finite types depend upon what requirement is imposed. For truth to be a Nash equilibrium, the following constraints must hold:

$$
\begin{aligned}
& \mathrm{U}^{1}\left(\mathrm{X}^{1}\left(\mathrm{n}^{1}\right)\right) \geq \mathrm{U}^{1}\left(\mathrm{X}^{2}\left(\mathrm{n}^{1}-1\right)\right) \\
& \mathrm{U}^{2}\left(\mathrm{X}^{2}\left(\mathrm{n}^{1}\right)\right) \geq \mathrm{U}^{2}\left(\mathrm{X}^{1}\left(\mathrm{n}^{1}+1\right)\right)
\end{aligned}
$$


Under this equilibrium notion, multiple equilibria in individual announcements can exist. A stronger requirement, that truthful revelation is a dominance-solvable equilibrium, guarantees that the Nash equilibrium is unique. The conditions that guarantee dominance solvability are:

Either

$$
\begin{aligned}
& \text { Either } \quad \begin{array}{l}
\mathrm{U}^{1}\left(\mathrm{X}^{1}\left(\mathrm{~N}^{1}+1\right)\right) \geq \mathrm{U}^{1}\left(\mathrm{X}^{2}\left(\mathrm{~N}^{1}\right)\right), 0 \leq \mathrm{N}^{1} \leq \mathrm{n}^{1}+\mathrm{n}^{2}-1 \\
\text { or } \quad \mathrm{U}^{2}\left(\mathrm{X}^{2}\left(\mathrm{~N}^{1}\right)\right) \geq \mathrm{U}^{2}\left(\mathrm{X}^{1}\left(\mathrm{~N}^{1}+1\right)\right), \mathrm{n}^{1} \leq \mathrm{N}^{1} \leq \mathrm{n}^{1}+\mathrm{n}^{2}-1 \\
\mathrm{U}^{2}\left(\mathrm{X}^{2}\left(\mathrm{~N}^{1}\right)\right) \geq \mathrm{U}^{2}\left(\mathrm{X}^{1}\left(\mathrm{~N}^{1}+1\right)\right), 0 \leq \mathrm{N}^{1} \leq \mathrm{n}^{1}+\mathrm{n}^{2}-1 \\
\mathrm{U}^{1}\left(\mathrm{X}^{1}\left(\mathrm{~N}^{1}+1\right)\right) \geq \mathrm{U}^{1}\left(\mathrm{X}^{2}\left(\mathrm{~N}^{1}\right)\right), 0 \leq \mathrm{N}^{1} \leq \mathrm{n}^{1}-1
\end{array}
\end{aligned}
$$

Condition (2a) imposes that telling the truth is a dominant strategy for type 1s. Condition (2b) then makes it a dominant strategy for type $2 \mathrm{~s}$ to reveal truthfully, given that type $1 \mathrm{~s}$ are telling the truth. Conditions (3) reverse this with telling the truth a dominant strategy for type $2 \mathrm{~s}$. Then, given that type $2 \mathrm{~s}$ are truthful, the type $1 \mathrm{~s}$ have a dominant strategy to be truthful. There is a tendency for (2) to be the appropriate restrictions for the planner when redistribution favors type 1s and (3) to be better when redistribution favors the type $2 \mathrm{~s}^{7}$

The planner's optimization problem denoted as (III) then is to choose the vectors $X^{1}\left(N^{1}\right)$ and $X^{2}\left(N^{1}\right)$ to maximize $\alpha n^{1} U^{1}\left(X^{1}\left(n^{1}\right)\right)+(1-\alpha) n^{2} U^{2}\left(X^{2}\left(n^{1}\right)\right)$ subject to $p \cdot\left(n^{1} X^{1}\left(n^{1}\right)+n^{2} X^{2}\left(n^{1}\right)\right) \leq 0$ and either (2) or (3). Note that, while the planner chooses allocations for every $\mathrm{N}^{1}$, which enter the incentive constraints, only the truthful revelation bundles $X^{1}\left(n^{1}\right)$ and $X^{2}\left(n^{1}\right)$ enter the objective function and resource constraint.

In specifying off-equilibrium bundles, an important issue arises of how individuals reveal their types to the planner. This is more complicated than in the Mirrlees-Stiglitz approach since, for the same revelation, an individual's bundle depends on what others reveal. In (III), the 
implicit assumption is that individuals simply announce their types without undertaking any action. Under this announcement revelation, bundles assigned to a type for one revelation pattern (one value of $\mathrm{N}^{1}$ ) can differ in all components than the bundles assigned that type for other revelation pattern. An alternative assumption made by Piketty is that individuals do not simply announce their types. Instead, they must perform an action that reveals the type they claim to be. Once the action is performed, it cannot be changed, so the planner is constrained to have the same level of that action in all bundles for a particular type for every $\mathrm{N}^{1}$ value. For example, an individual may reveal his type by earning the income designated for that type. The planner then can adjust the remaining components of an individual's consumption bundle depending upon what others reveal, but cannot alter the income level. This is action revelation.

Formally, assume that $\mathrm{X}_{1}^{\mathrm{i}}, \mathrm{i}=1,2$, is the labor income component of the net trade vector that is observed by the planner to determine an individual's type. This component must be the same in the bundles assigned in all revelation outcomes:

$$
X_{1}^{1}\left(N^{1}\right)=X_{1}^{1}\left(n^{1}\right) \text { and } X_{1}^{2}\left(N^{1}\right)=X_{1}^{2}\left(n^{1}\right), 0 \leq N^{1} \leq n^{1}+n^{2}
$$

Optimization problem (IV) is the same as (III) with the addition of the constraints in (4).

Clearly, any solution to (IV) is feasible in (III), but may not be optimal there. ${ }^{8}$ Piketty demonstrates that the solution to (IV) is generally better for the planner than the solution to (II). In effect, he shows that any first-best allocation can be implemented as the solution to (II) for some $\alpha$. It immediately follows that this will also be true in (III) as well. In this respect, action and announcement revelation are equivalent.

To see the intuition behind Piketty's result, consider the simplest case of an economy containing one individual of each type. We will show that an arbitrary first best allocation, that is, an allocation, which solves (I) for some $\alpha$, is also a solution to $(\mathbf{I V}){ }^{9}{ }^{\text {Let }} \mathrm{X}^{1}(1, \alpha)$ and 
$\mathrm{X}^{2}(1, \alpha)$ denote the solution to problem (I) for an arbitrary $\alpha$. Let $\mathrm{X}^{\mathrm{a}}$ and $\mathrm{X}^{\mathrm{b}}$ denote the bundles chosen by the two individuals by name and not type. After individuals reveal their type by choosing an action, there are three possible information sets assuming that the individuals have chosen actions consistent with the first best allocations $X^{1}(1, \alpha)$ : both individuals have chosen the action of type $1, X_{1}^{a}=X_{1}^{b}=X_{1}^{1}(1, \alpha)$, both have chosen the action of type $2, X_{1}^{a}=X_{1}^{b}=X_{1}^{2}(1, \alpha)$, or exactly one individual has chosen the action of each type, $\mathrm{X}_{1}^{\mathrm{a}}=\mathrm{X}_{1}^{1}(1, \alpha)$ and $\mathrm{X}_{1}^{\mathrm{b}}=\mathrm{X}_{1}^{2}(1, \alpha)$ or $\mathrm{X}_{1}^{\mathrm{a}}=\mathrm{X}_{1}^{2}(1, \alpha)$ and $\mathrm{X}_{1}^{\mathrm{b}}=\mathrm{X}_{1}^{1}(1, \alpha)$. In the first two cases, the planner knows one person has lied but does not know which it is. The planner must treat them identically since there is no basis upon which to distinguish them. In the third case, both may have lied or both may have told the truth. The planner may have beliefs about whether both have lied but cannot observe this. Hence, the planner must assign the same bundle to the individual choosing $X_{1}^{1}(1, \alpha)$ whether that individual is named $a$ or $b$.

Given these information sets, the planner chooses consumption levels $X_{2}(0),\left(X_{2}^{1}(1), X_{2}^{2}(1)\right)$, and $X_{2}(2)$. If the first best is to be the Nash equilibrium, then the information set on the equilibrium path must be that with one individual choosing each income level and $X_{2}^{1}(1)=X_{2}^{1}(1, \alpha)$ and $X_{2}^{2}(1)=X_{2}^{2}(1, \alpha)$. For this to be an equilibrium, the policies $\left(X_{2}(0),\left(X_{2}^{1}(1), X_{2}^{2}(1)\right), X_{2}(2)\right)$ must induce the individuals to choose the right action.

If $\mathrm{p} \cdot \mathrm{X}^{1}(1, \alpha)>0$, the off-equilibrium bundles can be chosen to satisfy the dominance solvability conditions (2) of problem (IV) which in this special case reduce to:

$$
\begin{aligned}
& \mathrm{U}^{1}\left(\mathrm{X}_{1}^{1}(1, \alpha), \mathrm{X}_{2}^{1}(1)\right) \geq \mathrm{U}^{1}\left(\mathrm{X}_{1}^{2}(1, \alpha), \mathrm{X}_{2}(0)\right) \\
& \mathrm{U}^{1}\left(\mathrm{X}_{1}^{1}(1, \alpha), \mathrm{X}_{2}(2)\right) \geq \mathrm{U}^{1}\left(\mathrm{X}_{1}^{2}(1, \alpha), \mathrm{X}_{2}^{2}(1)\right)
\end{aligned}
$$




$$
\mathrm{U}^{2}\left(\mathrm{X}_{1}^{2}(1, \alpha), \mathrm{X}_{2}^{2}(1)\right) \geq \mathrm{U}^{2}\left(\mathrm{X}_{1}^{1}(1, \alpha), \mathrm{X}_{2}(2)\right)
$$

To show that a solution to (I) will also solve (IV), it suffices to show that it is feasible in (IV), since it must then be optimal. In turn, feasibility in (IV) follows if 5(a-c) are satisfied. To satisfy $5(a), X_{2}(0)$ can equal any amount below the type 1 indifference curve through $X^{1}(1, \alpha)$ on the vertical line through $X_{1}^{2}(1, \alpha)$. Because of single crossing, on the vertical line through $X_{1}^{1}(1, \alpha)$, the indifference curve of the type 1's through the $X^{2}(1, \alpha)$ bundle must be below the type 2 indifference curve through $\mathrm{X}^{2}(1, \alpha)$. Setting $\mathrm{X}_{2}(2)$ equal to any amount above the type 1 indifference curve and below the type 2 indifference curve satisfies 5(b) and 5(c). See Figure 1. A similar argument using (3) can be shown if $\mathrm{p} \cdot \mathrm{X}^{1}\left(\mathrm{n}^{1}, \alpha\right)<0$.

Piketty places no restrictions on the consumption component of the off-equilibrium bundles $\left(\mathrm{X}^{\mathrm{i}}\left(\mathrm{N}^{\mathrm{i}}\right), \mathrm{N}^{\mathrm{i}} \neq \mathrm{n}^{\mathrm{i}}\right)$ other than what is needed to sustain the desired first-best allocation as a unique Nash equilibrium. It does not seem reasonable to allow these off-equilibrium bundles to be completely arbitrary with the planner facing no constraints in choosing them. Even in a oneshot game such as that considered here, some restrictions on these bundles would seem appropriate. To start with, if some set of off-the-equilibrium-path bundles which are needed to sustain a first-best allocation run a deficit for the government, then this would not be feasible if that revelation pattern arose. Even if the government announced such bundles, they could not be implemented, and hence, would not be believed by individuals who would recognize that adjustments would be necessary to maintain feasibility. As shown below under action revelation, this possibility arises for some first-best allocations. To rule out this situation, the resource constraint can be extended to:

$$
\mathrm{p} \cdot\left(\mathrm{N}^{1} \mathrm{X}^{1}\left(\mathrm{~N}^{1}\right)+\left(\mathrm{n}-\mathrm{N}^{1}\right) \mathrm{X}^{2}\left(\mathrm{~N}^{1}\right)\right) \leq 0,0 \leq \mathrm{N}^{1} \leq \mathrm{n}^{1}+\mathrm{n}^{2}
$$


If the off-equilibrium bundles instead yielded a government surplus, this would be feasible, but of course, it could not be optimal. Again, individuals would not necessarily believe that the government would implement the announced bundles. Hence, the only allowed bundles would be those exactly balancing the budget in all states. This strengthens (6) to:

$$
\mathrm{p} \cdot\left(\mathrm{N}^{1} \mathrm{X}^{1}\left(\mathrm{~N}^{1}\right)+\left(\mathrm{n}-\mathrm{N}^{1}\right) \mathrm{X}^{2}\left(\mathrm{~N}^{1}\right)\right)=0,0 \leq \mathrm{N}^{1} \leq \mathrm{n}^{1}+\mathrm{n}^{2}
$$

The problem with a surplus is the credibility of the commitment, which is a weaker concern than that of the infeasibility of a deficit. Once credibility becomes an issue, then even off-equilibrium announcements which balance the budget may not be believable if they are not optimal for the government to carry out. If the government has an opportunity to readjust to meet a deficit or to allocate a surplus, then it would also have the opportunity to reoptimize and to change an allocation which does not maximize social welfare.

Allowing such reoptimization raises more issues. If the government could reoptimize off the equilibrium path, then it could reoptimize on the path as well, which would almost immediately rule out distorted bundles (under announcement revelation). If there were no commitment to the planner's announced schedules, then such announcements would be completely irrelevant. One possible solution to some of these difficulties is to assume that the government can partially commit to its initial announcements. Due to the possibility of legal action, the government might not be able to make changes which would lower the utility of someone who has revealed her type truthfully. That is, a policy change which affects those who reveal themselves to be of a certain type could not lower the utility of someone of that type. However, the policy change could harm someone who has misrevealed, since an individual without "clean hands" would have his case thrown out of court. In this respect, our partial commitment differs in spirit from renegotiation in games (see, for example, Farrell and Maskin 
[1989]) and in principal-agent problems (see, for example, Fudenberg and Tirole [1990]), where renegotiation must lead to a Pareto improvement. Baron and Besanko [1987] analyze a principal-agent model in which the principal can guarantee only that any truth-telling agent will earn nonnegative profit in the second period of a regulatory regime. Our partial commitment is similar in spirit, except that we allow the principal to guarantee any feasible utility level to truthtelling agents (and to condition the levels of these guarantees on the aggregate reports).

The game we develop to incorporate the restrictions on the government's ability to revise its announced policies has four stages. In the first stage, nature moves to assign a type to each individual. The aggregate distribution is known to all individuals and the planner, but the type of a particular individual is known only by that individual. In the second stage, the planner announces the proposed taxes or redistributions that will occur in each circumstance. Since the planner can update, these announcements in effect specify some limitations on the actual policies to be imposed later in the game. In the third stage, the individuals, having observed the planner's initial announcements, reveal their types to the planner either by announcement or action and are committed to that revelation in the remainder of the game. In the fourth stage, given the individuals' revelations and the limitations from its own first stage announcements, the planner specifies the actual taxes or redistributions that will occur. We solve for the sequential equilibrium of the four-stage game. ${ }^{10}$ As we will discuss below in specific cases, to complete the specification of the game, the preferences of the planner off the truthful revelation path when some individuals have revealed falsely must be specified. The planner may or may not alter its preferences with respect to the utility of individuals who have lied. 
In the next sections, we consider the implications of the restrictions of feasibility, budget balance, and partial commitment on equilibrium outcomes in various cases depending on the type of revelation and the number of individuals.

\section{Off-Equilibrium Budget Balance Restrictions}

With announcement revelation, the planner has sufficient flexibility in specifying offequilibrium bundles that imposing off-equilibrium budget balance is not a binding restriction as shown in Theorem 1.

Theorem 1: Under announcement revelation, for any first best allocation (that is, any allocation solving (I) for some $\alpha$ ), there exist $\mathrm{X}^{1}\left(\mathrm{~N}^{1}\right)$ and $\mathrm{X}^{2}\left(\mathrm{~N}^{1}\right)$ for all $\mathrm{N}^{1}$ which satisfy budget balance $p \cdot\left(N^{1} X^{1}\left(N^{1}\right)+\left(n-N^{1}\right) X^{2}\left(N^{1}\right)\right)=0$ and which satisfy the dominance solvability constraints (2) or (3).

Proof: All proofs are contained in the appendix.

Although off-equilibrium budget balance restrictions are irrelevant for announcement revelation, they can have a significant impact when action revelation occurs. To see this, consider the case of two individuals when $n^{1}$ and $n^{2}$ both equal 1 . In the previous section, we constructed off-equilibrium bundles consistent with action revelation which sustain the first best. Now consider the no-deficit and no-surplus conditions off-equilibrium. Since the type 1 indifference curve through $X^{1}(1, \alpha)$ lies above the line $p \cdot X=0$, and condition (5a) is satisfied

by any bundle $\left(X_{1}^{2}(1, \alpha), X_{2}(0)\right)$ below that indifference curve, then $X_{2}(0)$ can always be chosen to balance the budget. However, as shown in Figure 1, no $\mathrm{X}_{2}(2)$ may exist which satisfies (5b) and (5c) and which balances the budget. In Figure 1, every such bundle lies above 
the $\mathrm{p} \cdot \mathrm{X}=0$ line, hence runs a deficit. In that example, no feasible allocation exists when both individuals report they are type 1 to sustain that first best allocation. Alternatively, the interval might lie below the $\mathrm{p} \cdot \mathrm{X}=0$ line and the first best allocation cannot be sustained unless a surplus is run when the type 2 individual mimics the other type's action. From single crossing, at $\mathrm{X}^{1}(1, \alpha)$ the type 2 indifference curves through $\mathrm{X}^{2}(1, \alpha)$ must lie above the type 1 indifference curve through $\mathrm{X}^{2}(1, \alpha)$. Hence, a deficit is necessary if that type 1 indifference curve lies above the $\mathrm{p} \cdot \mathrm{X}=0$ line at $\mathrm{X}_{1}^{1}(1, \alpha)$ and a surplus is necessary if that type 2 indifference curves lies below the $\mathrm{p} \cdot \mathrm{X}=0$ line at $\mathrm{X}_{1}^{1}(1, \alpha)$. Otherwise budget balance is possible.

The following result gives sufficient conditions on individual preferences and $\alpha$ such that the solution to (IV) requires an off-equilibrium deficit or surplus or allows for budget balance. Theorem 2: Consider an economy with one individual of each type with action revelation. When redistribution is toward the type $1 \mathrm{~s}\left(\mathrm{p} \cdot \mathrm{X}^{1}(1, \alpha)>0\right)$ :

(A) For $\alpha$ near the no-redistribution $\alpha^{\circ}, \mathrm{X}_{2}(2)$ can always be chosen to ensure off-equilibrium path budget balance while sustaining the allocation $X^{1}(1, \alpha), i=1,2$.

(B) If first-best type 1 labor income $\mathrm{X}_{1}^{1}(1, \alpha)$ is bounded away from 0 as $\alpha$ increases, then for sufficiently large $\alpha$, an off-equilibrium surplus is required to sustain $\mathrm{X}^{\mathrm{i}}(1, \alpha), \mathrm{i}=1,2$.

(C) If there exists an $\hat{\alpha}$ such that $X_{1}^{1}(1, \alpha)=0$ for $\hat{\alpha}<\alpha \leq 1$, then a deficit off the equilibrium path is required to sustain the allocations $\mathrm{X}^{\mathrm{i}}(1, \alpha), \mathrm{i}=1,2$.

Consider several points about Theorem 2. First, the sufficient condition in Theorem 2 (B) for a surplus to be required when the type 2 individual misreveals is satisfied if the type 1's 
demand for leisure is unaffected by the amount of redistribution $\left(\partial \mathrm{X}_{1}^{1}(1, \alpha) / \partial \alpha=0\right)$. Second, the conditions in Theorem 2 under which budget balance must be violated off the equilibrium path in order to sustain the first best on the equilibrium path are sufficient but not necessary. For example, the sufficient condition in Theorem 2 (C) for infeasibility is only one of many possibilities. Another condition is if type 1's demand for consumption is unaffected by lumpsum redistribution $\left(\partial \mathrm{X}_{2}^{1}(1, \alpha) / \partial \alpha=0\right)$ then the off-equilibrium path allocations must be infeasible. Third, the condition in Theorem 2 (A) can be extended for some set of individual preferences. When $\mathrm{X}_{1}^{1}(1, \alpha)>0$ for all $\alpha$ but is not bounded away from zero, it may be possible to sustain any first-best allocation with budget balance. What is required is that $\left.\mathrm{U}^{1}\left(\mathrm{X}_{1}^{1}(1, \alpha), \mathrm{X}_{1}^{1}(1, \alpha)\right) \leq \mathrm{U}^{1}\left(\mathrm{X}^{2}(1, \alpha)\right)\right)$ and $\mathrm{U}^{2}\left(\mathrm{X}^{2}(1, \alpha)\right) \geq \mathrm{U}^{2}\left(\mathrm{X}_{1}^{1}(1, \alpha), \mathrm{X}_{1}^{1}(1, \alpha)\right)$. If this holds for all $\alpha$, the achievable utility possibility frontier in problem (IV) will be identical to the fullinformation utility possibility frontier. For other preferences it will have portions interior to the full-information frontier. When the full-information frontier cannot be achieved, the pattern of optimal distortions can differ from those in the standard self-selection model in problem (II). Theorem 3: (A) If the no-deficit constraint binds off the equilibrium path, then, on the equilibrium path, both types consume distorted bundles with $\mathrm{MRS}^{1}>1$ and $\mathrm{MRS}^{2}<1$. In addition, the planner is doing excessive redistribution in the sense that, if the incentive constraints were removed but the incomes were fixed, the planner would gain by reducing the consumption transfer from 2's to 1's.

(B) If the no-surplus constraint binds, then, on the equilibrium path, the type 2 bundle is undistorted, but for type 1 's, $\mathrm{MRS}^{1}<1$. In addition, the planner is doing insufficient 
redistribution in the sense that, if the incentive constraint were removed but incomes were fixed, the planner would gain by increasing the consumption transfer from 2's to 1's.

While the pattern of distortions in the case when the no-surplus constraint binds is the same as in the standard Mirrlees-Stiglitz model, it is quite different when the no-deficit constraint binds. Both types consume distorted bundles, not just the type who gains from the redistribution; the type paying taxes faces a positive marginal tax rate, while the subsidized type faces a negative marginal tax rate..

The achievable utility possibility frontiers derived from problem (II) and problem (IV) with off-equilibrium budget balance required show certain qualitative features. Both coincide with the full-information frontier near the no-redistribution point, but for large redistributions they may lie below the full-information frontier. Quantitatively, how they compare is ambiguous. The problem (IV) frontier can coincide with the full-information frontier over a larger range. Indeed, as argued above, it is possible that they will be identical, whereas the problem (II) achievable frontier must diverge from the full-information one. On the other hand, the problem (IV) frontier may diverge from the full-information frontier when the problem (II) frontier still coincides with it. Consider Figure 2. This shows the situation in which the value of $\alpha$, denoted $\bar{\alpha}$, is such that the level of redistribution has just reached the point where the standard self-selection constraint of type 2 binds. Further redistribution must entail distortions. This bundle might be achievable in (IV) with off-equilibrium budget balance if type 1's indifference curve through $X^{2}(1, \bar{\alpha})$ lies below the $\mathrm{p} \cdot \mathrm{X}=0$ line at $\mathrm{X}_{1}^{1}(1, \bar{\alpha}) . \quad$ In Figure 2 , however, that indifference curve lies above that line, so an off-equilibrium deficit results. Hence, the problem (IV) frontier must have already diverged from the full-information frontier. 
To conclude this section, we consider the effect of increasing the number of individuals of each type on the set of undistorted allocations, which can be sustained under action revelation with off-equilibrium budget balance. As shown in Theorem 4, having more individuals may relax or tighten the planner's constraints.

Theorem 4: As the economy is replicated, the set of first best allocations which can be sustained in problem (IV) can expand or contract.

Clearly, from this result, the failure to be able to sustain all first best allocations as given in Theorem 2 under action revelation was not an artifact of having just two individuals. With more individuals, it is even possible that fewer first best allocations can be sustained. On one hand, with more individuals, there are more off-equilibrium budget balance restrictions. On the other hand, the incentive constraints are relaxed. Having more individuals places intermediate bundles between $X^{1}\left(n^{1}, \alpha\right)$ and $X^{2}\left(n^{1}, \alpha\right)$, which the planner has some flexibility in choosing.

This can help overcome the preference of type $2 \mathrm{~s}$ for the first best bundle of type $1 \mathrm{~s}$ when there is significant redistribution toward type 1s. Which of these effects dominates depends upon preferences as shown in the proof for the case with four individuals. Whether the type 1 indifference curve through the no redistribution bundle $\mathrm{X}(4)$ intersects the vertical line through $\mathrm{X}_{1}^{2}(1, \hat{\alpha})$ above or below the $\mathrm{p} \cdot \mathrm{X}=0$ line depends upon how much curvature the indifference curves have and how close $X_{1}^{1}(1, \hat{\alpha})$ and $X_{1}^{2}(1, \hat{\alpha})$ are to each other. The more they differ, the more likely it is that more efficient redistribution can be done when there are more individuals.

Finally, note that similar ambiguities exist in the effect of increasing $n^{1}$ and $n^{2}$ above 2 each. More nondistorting redistribution may be possible when $n^{1}=n^{2}=3$ than at $n^{1}=n^{2}=1$ even though less was possible when $n^{1}=n^{2}=2$. It is an open question whether one of the effects 
can be shown to dominate as $n^{1}$ and $n^{2}$ get large so that one can say how the maximum efficient redistribution in large economies compares to that in an economy with only one individual of each type.

\section{Reoptimization with Partial Commitment}

In addition to deviating from the announced bundles in order to satisfy budget balance, the planner might benefit from altering the bundles it initially announced both on and off the equilibrium path. Consider first the case of action revelation. From Theorem 3, it follows that if the planner faced no constraints on its ability to change consumption once individuals had made their income decisions, it would change the equilibrium consumptions whenever either the nosurplus or no-deficit constraints were binding off the equilibrium path. This follows since distortions are optimal in these cases and the social marginal utilities of consumption are not equal across individuals. If this were allowed, individuals would recognize that this would occur and would alter their behavior when choosing their incomes, thus limiting the planner's ability to redistribute. To prevent this, a constraint that $\alpha \mathrm{U}_{2}^{1}\left(\mathrm{X}_{1}^{1}, \mathrm{X}_{2}^{1}\right)=(1-\alpha) \mathrm{U}_{2}^{2}\left(\mathrm{X}_{1}^{2}, \mathrm{X}_{2}^{2}\right)$ could be added to problem (IV). The planner would then have no desire to alter the announced consumptions. This could be quite restrictive.

Our approach instead is to impose constraints on the planner's ability to change its announced plans. These constraints are the restrictions of partial commitment described in Section 2. No individual who revealed truthfully can be worse off after the reoptimization than he or she would have been under the initial announcement. This reduces the initial announcements to utility guarantees in each information set. Assume the planner initially announced $\mathrm{X}^{1}\left(\mathrm{~N}^{1}\right)$ and $\mathrm{X}^{2}\left(\mathrm{~N}^{1}\right)$ if $\mathrm{N}^{1}$ individuals revealed themselves as type $1 \mathrm{~s}$. If $\mathrm{N}^{1}$ is the 
number revealed, the planner cannot alter $\mathrm{X}_{1}^{\mathrm{i}}\left(\mathrm{N}^{1}\right)$ but can choose a new budget balancing $\mathrm{X}_{2}^{\mathrm{i}}$ so long as $\mathrm{U}^{\mathrm{i}}\left(\mathrm{X}_{1}^{\mathrm{i}}\left(\mathrm{N}^{1}\right), \mathrm{X}_{2}^{\mathrm{i}}\right) \geqq \mathrm{U}^{\mathrm{i}}\left(\mathrm{X}^{\mathrm{i}}\left(\mathrm{N}^{1}\right)\right)$.

The following result shows that, with action revelation, partial commitment sufficiently limits the planner's ability to reoptimize that the outcome with the constrained reoptimization is equivalent to that without the possibility of reoptimization but with budget balance required in all states.

Theorem 5: Under action revelation, the equilibrium with constrained reoptimization is the same as when the budget must be balanced on and off the equilibrium path but there is no possibility of reoptimization.

In part, this result depends upon the assumption that there are only two components to the bundles. Once income is fixed only consumption can vary and the two types have identical preferences over changes in consumption alone. In this case, it is relatively easy to make any reoptimization infeasible. On the other hand, under announcement revelation, the additional flexibility available to the planner in choosing both components for each value of $\mathrm{N}^{1}$ makes reoptimization even with partial commitment a significant factor even as it made off-equilibrium budget balance restrictions unimportant. The off-equilibrium budget balancing bundles needed for Theorem 1 may not be credible since the planner may not be willing to actually impose them when some individuals misreveal.

To analyze this, we must specify what the planner will do (or more importantly what individuals believe the planner will do) when optimizing both on and off the equilibrium path. This requires individuals to know more about social preferences than just which allocation on the Pareto frontier the planner wants to sustain. This can be complicated if the planner does not 
maximize a single welfare function but has different preferences depending upon how many individuals reveal themselves to be of each type. The planner might place different weights on the welfare of truthful revealers and misrevealers. In the extreme, the planner could disregard the liar's utility. With such preferences, in a world with one individual of each type, the planner would choose $\mathrm{X}(0)$ to be the bundle, which maximizes $\mathrm{U}^{2}(X)$ along the $\mathrm{p} \cdot \mathrm{X}=0$ line and $\mathrm{X}(2)$ to be the bundle, which maximizes $\mathrm{U}^{1}(\mathrm{X})$ along the same line. In the other extreme, the planner would continue to maximize $\alpha \mathrm{U}^{1}(\mathrm{X})+(1-\alpha) \mathrm{U}^{2}(\mathrm{X})$ even though someone had lied. Then $\mathrm{X}(0)$ and $\mathrm{X}(2)$ would be a bundle lying between 1's and 2's most preferred bundles on the $\mathrm{P} \cdot \mathrm{X}=0$ line. In between these polar cases are intermediate cases where the social welfare weight would vary with the aggregate announcement. Let $\alpha(0), \alpha(1)$, and $\alpha(2)$ be the weights if 0,1 and 2 people reveal themselves as type 1 s. Then $\alpha(0) \leq \alpha(1) \leq \alpha(2)$ would hold. Let $\hat{X}(0)$ and $\hat{X}(2)$ be the social welfare-maximizing bundle on the line $\mathrm{p} \cdot \mathrm{X}=0$ when $\alpha$ equal $\alpha(0)$ and $\alpha(2)$ respectively.

As a preliminary benchmark, consider a situation in which the planner cannot commit to carry out any announcements made in stage 2 . In this case, the planner will implement whatever bundle optimizes social welfare given the available information after individuals have announced their types. When one individual has lied so that $\mathrm{N}^{1}$ equals either 0 or 2 , the planner implements the bundle $\hat{\mathrm{X}}\left(\mathrm{N}^{1}\right)$. When $\mathrm{N}^{1}=1$ (either none or both misreveal), the planner implements the first-best bundles $X^{1}(1, \alpha)$ and $X^{2}(1, \alpha)$. The individuals foresee this when making their announcement decisions. The dominance solvability conditions are now:

$$
\mathrm{U}^{1}\left(\mathrm{X}^{1}(1, \alpha)\right) \geq \mathrm{U}^{1}(\hat{\mathrm{X}}(0))
$$




$$
\begin{aligned}
& \mathrm{U}^{1}(\hat{\mathrm{X}}(2)) \geq \mathrm{U}^{1}\left(\mathrm{X}^{2}(1, \alpha)\right) \\
& \mathrm{U}^{2}\left(\mathrm{X}^{2}(1, \alpha)\right) \geq \mathrm{U}^{2}(\hat{\mathrm{X}}(2))
\end{aligned}
$$

Since $\mathrm{X}^{1}(1, \alpha)$ is the best bundle for a type 1 on a budget line with more resources than $\hat{X}(0)$, (7a) must be satisfied for all $\alpha(0)$. Condition (7b) is least likely to be satisfied if $\hat{X}(2)$ equals type 2's best bundle on the line $\mathrm{p} \cdot \mathrm{X}=0, \mathrm{X}^{2}\left(1, \alpha^{\mathrm{o}}\right)$. Since neither consumption nor leisure is inferior, then from monotonicity, $\mathrm{U}^{1}\left(\mathrm{X}^{2}\left(1, \alpha^{0}\right)\right)>\mathrm{U}^{1}\left(\mathrm{X}^{2}(1, \alpha)\right)$, any $\alpha>\alpha^{0}$. Therefore (7b) will be satisfied for all $\alpha(2)$. Whether or not (7c) is satisfied determines if the equilibrium involves truthful revelation with redistribution or has type 2 s misrevealing with no redistribution possible. Perhaps paradoxically, only a planner desiring to do a small amount of redistribution is able to do any.

Theorem 6: Consider announcement revelation in an economy with $n^{1}=n^{2}=1$. Assume that the planner cannot commit to bundles announced prior to individual revelation. The equilibrium is the first-best allocation for any $\alpha$ near $\alpha^{0}$. There exists some $\bar{\alpha}$ above $\alpha^{0}$ such that, for all $\alpha$ greater than $\bar{\alpha}$, the equilibrium allocation is the Pareto inferior allocation $\hat{X}(2)$. The less weight the planner gives to an individual who lies, the larger is the first interval and the smaller is the second. Similarly, there exists an $\overline{\bar{\alpha}}$ below $\alpha^{0}$ such that the equilibrium allocation is the Pareto inferior allocation $\hat{X}(0)$.

Figure 3 shows the attainable utility possibility frontier in this circumstance. The point at which the outcome moves from the first-best frontier to the interior of the Pareto frontier has no clear relationship to the points at which in the Stiglitz problem (II) the constrained utility possibility frontier begins to differ from the first best frontier. If liars are given no weight, $\alpha(2)$ 
$=1$, then the first best segment in Figure 3 will be larger than that for problem (II). If the utility of liars is not discounted, $(\alpha(2)=\alpha)$, then no definite comparison can be made.

It is worth noting that the planner cannot commit to use any value of $\alpha(2)$ other than its true value of $\alpha(2)$, whatever it is. The planner might do better acting as if $\alpha(2)=1$ even if it were not but assertions of this in early stages would not be believed by type 2 individuals.

As discussed above, allowing completely unconstrained reoptimization may be too strong an assumption. In stage two, the planner can make initial announcements of tax policies which confer on any individual who reveals his type correctly an entitlement not to be made worse off by reoptimization than if the initial policies were carried out. Consider the off-equilibrium outcome when both individuals announce that they are type 1 . As argued in Theorem 6, the planner does best in the truthful revelation equilibrium if liars are given no weight so $\alpha(2)=1$. Assume that the planner in stage two announces that $X(2)=X^{1}\left(1, \alpha^{0}\right)$, type 1's most preferred no-redistribution bundle. If $\alpha$ (2) were less than 1 , without commitment, the planner would deviate from this bundle in stage four. With partial commitment, the planner can no longer do this, since any change would lower the utility of a type 1 who revealed truthfully, thus violating the entitlement. No other stage two announcement can do better for the planner. Any other X(2) whether closer or further from the origin than $X^{1}\left(1, \alpha^{0}\right)$ will give flexibility to the planner in stage four. This will be recognized by the type 2 individuals who will have increased incentives to misreveal in stage three. Hence, under partial commitment, the planner can be viewed as setting a utility level for type $2 \mathrm{~s}$ who misreveal of $\hat{U}^{2}(2)=\mathrm{U}^{2}\left(\mathrm{X}^{1}\left(1, \alpha^{o}\right)\right)$. Partial commitment in effect allows the planner to act in stage four as if $\alpha(2)$ equals 1 , even when it is actually less than 1. 
Similarly, if the type 1 were to lie and both claimed to be type 2 , the planner by announcing that $X(0)=X^{2}\left(1, \alpha^{\circ}\right)$ would lock itself in to acting as if it gave no weight to the lying individual with $\alpha(0)=0$. No deviation in stage four would be possible since this would violate the entitlement to the truthful type 2. The planner gains by making this commitment in stage two since it makes the stage three incentive constraint on type 1s not lying when type $2 \mathrm{~s}$ are truthful as strong as possible. Hence, the planner in stage two acts as if it set a utility level for type 1's who misreveal of $\hat{U}^{1}(0)=U^{1}\left(X^{2}\left(1, \alpha^{0}\right)\right)$.

Partial commitment also constrains the planner's ability to reoptimize on the equilibrium path when both individuals announce truthfully. Given the above entitlements, the stage three incentive constraints on individuals are now:

$$
\begin{aligned}
& \mathrm{U}^{1}\left(\mathrm{X}^{1}(1, \alpha)\right) \geq \mathrm{U}^{1}(0) \\
& \mathrm{U}^{1}\left(\mathrm{X}^{1}\left(1, \alpha^{0}\right)\right) \geq \mathrm{U}^{1}\left(\mathrm{X}^{2}(1, \alpha)\right) \\
& \mathrm{U}^{2}\left(\mathrm{X}^{2}(1, \alpha)\right) \geq \hat{\mathrm{U}}^{2}(2)
\end{aligned}
$$

Conditions (8a) and (8b) never bind. For $\alpha \geq \alpha^{\circ}$, in each case, the LHS bundle is the best for type 1 on a budget line with more net resources than the RHS bundle which is not type 1's best bundle given the resource constraint. Thus (8c) is the binding incentive constraint. Since $\hat{\mathrm{U}}^{2}(2)<\mathrm{U}^{2}(\hat{\mathrm{X}}(2))$, although (8c) will bind for sufficiently large $\alpha$, this will occur at an $\alpha$ greater than that at which $(7 \mathrm{c})$, the no-commitment incentive constraint, first binds. Denote the smallest $\alpha$ at which (8c) binds as $\bar{\alpha}$. Then for $\alpha$ between $\alpha^{\circ}$ and $\bar{\alpha}$, if the planner announces the bundles $X^{1}(1, \alpha)$ and $X^{2}(1, \alpha)$ in stage 2 , then they will be the unique equilibrium outcomes in the game. For $\alpha$ greater than $\bar{\alpha}$, if these bundles are announced then the planner would 
implement them in stage four causing misrevelation in stage three. However, the planner can instead announce $\mathrm{X}^{1}(1, \bar{\alpha})$ and $\mathrm{X}^{2}(1, \bar{\alpha})$ whenever $\alpha$ is greater than $\bar{\alpha}$. In stage four, the planner would like to do more redistribution than these entail, but this would violate the entitlement given to type 2's.

Theorem 7: Consider announcement revelation in an economy with $n^{1}=n^{2}=1$. When the planner can reoptimize subject to the partial commitment and budget balance constraints, then for each value of $\alpha$, there is a unique equilibrium outcome and this outcome lies on the first-best utility possibility frontier for all values of $\alpha$. For a range of $\alpha$ including 1 , the same point on the utility possibility frontier is achieved so that, while undistorted, the allocations entail less than the optimal amount of redistribution. The set of achievable first-best allocations exceeds that achievable when no commitment is possible in Theorem 6 or in the Stiglitz problem (II), but it cannot be compared to that achievable with action revelation as given in Theorems 2 and 5 .

In Theorems 6 and 7, there was only one individual of each type. The planner faced only a small number of information sets. In the two information sets in which one individual misrevealed, both individuals then claimed to be of the same type, so they had to be treated identically. This reduced the flexibility available to the planner in reoptimization in these information sets, since it could only choose a single bundle on the $\mathrm{p} \cdot \mathrm{X}=0$ line.

When the economy has more than one agent of each type, after misrevelation the planner retains considerable flexibility. As long as some agents claim to be of different types, the planner can redistribute between those reporting different types. In choosing the original utility commitment levels, the planner chooses how much in resources to give each group and not simply how to balance off their preferences in choosing a zero-redistribution bundle. 
The key result is adding more consumers of both types proportionately permits more redistribution

Theorem 8: Under announcement revelation and partial commitment, for economies with equal numbers of both types of individuals $\left(n^{1}=n^{2}\right)$, when $\alpha>\alpha^{0}$, a proportional increase in the number of both types permits the planner to transfer more resources per capita from type $2 \mathrm{~s}$ to type $1 \mathrm{~s}$.

We have formally shown that it is possible to do more redistribution with $n^{1}=n^{2}>4$ than the maximum redistribution with $n^{1}=n^{2}=4$. The same logic can be used to show that the maximum redistribution for a given number of workers can be improved upon when there are more workers of both types in proportion by reverting to the no-redistribution bundles when large numbers of type 2's misreport and using bundles analogous to those in Figure 6 when only a small number misreport. Thus, more of the full-information frontier is sustainable as dominancesolvable equilibria as the number of workers of both types grows.

It is an open question whether this process continues without any bound so that the entire full-information Pareto frontier can be implemented as dominance solvable equilibria with partial commitment when the number of consumers is large.

\section{Conclusions}

When there are a finite number of individuals and the planner has precise information about the aggregate distribution of types, the planner can determine if some individuals have misrevealed. Reasonable restrictions on the taxes the planner can impose when such misrevelation occurs significantly effect the equilibrium taxes which can be implemented under a dominance solvable mechanism. These equilibrium taxes can differ from those in the standard 
Mirrlees-Stiglitz analysis with an infinite number of consumers where off-equilibrium situations are not detected and from those in the analysis of Piketty with a finite number of individuals in which no off-equilibrium path restrictions were imposed. The effect of the off-equilibrium restrictions depends crucially on whether individuals reveal their type to the planner by a simple announcement or by taking an action such as choosing a level of income.

When action revelation by individuals occurs, only budget balance off the equilibrium path matters. The set of first best allocations which can be implemented is generally less than those in Piketty where every first best allocation was implementable. However, the set of implementable first best allocations in this case is not directly comparable to those in MirrleesStiglitz. Depending on individual preferences, it may be larger or smaller. In addition, when the restriction of no off-equilibrium path deficits is binding and a first best allocation is not implementable, then the pattern of equilibrium distortions is quite different from those in the standard model. Both types are distorted with one subsidized on the margin to work more than under lump sum taxation and one taxed on the margin to work less..

When announcement revelation occurs, imposing off-equilibrium budget balance does not alter the Piketty result. Every first best allocation is implementable. Imposing the possibility of reoptimization with partial commitment off the equilibrium path does limit the set of implementable first best allocations, but this set is larger than in the standard Mirrlees-Stiglitz analysis.

Comparing the outcomes under announcement and action revelation is interesting. It might be thought that more allocations could be implemented with announcement revelation than action revelation since action revelation imposes extra constraints on the planner. When only budget balance is required this occurs. The set of implementable first best allocations is smaller 
under action revelation than under announcement revelation. However, with partial commitment reoptimization, the outcome under announcement revelation does not necessarily dominate that under action revelation. Having reoptimization as a possibility means that the equilibrium is no longer a simple optimization problem for which the addition of a constraint cannot be beneficial. There are actually three separate optimizations in stage four whose solutions are compared by individuals in order to make stage three decisions. The action revelation constraint may harm the planner in each of these optimizations individually but help in the overall problem. By allowing a worse result in one of the off-equilibrium optimizations, the prior stage revelation constraint is relaxed, sometimes helping the planner. In effect, the additional constraints of action revelation can act as a form of additional commitment limiting reoptimization. In the case of two argument utility functions considered here, this can be powerful. Once income is fixed, especially off the equilibrium path, the planner has little flexibility in reoptimizing since only consumption, constrained by budget balance, can be varied.

Two crucial factors in the analysis are the budget balance requirements off the equilibrium path and the planner's precise knowledge of the distribution of types. The significance of budget balance is highlighted by comparing the result in the optimal tax context to the related situation of a discriminating monopolist. Levine and Pesendorfer [1995] analyze a monopolist selling to a finite set of customers who can fully commit to contract offers. In results analogous to those of Piketty, they show that the monopolist can fully extract the surplus from consumers. Hamilton and Slutsky [2002] impose restrictions similar to the ones in this paper, of dominance solvability and reoptimization with partial commitment both on and off the equilibrium path. The full surplus extraction result of Levine and Pesendorfer [1995] continues to hold unlike our result for taxation. The difference is the absence of budget balance 
restrictions. However, if a nonnegative profit condition is imposed for every pattern of revelation and not just for the truthful pattern, then full extraction no longer occurs.

That the planner has exact information about the aggregate distribution of types can be relaxed somewhat. For example, assume that there are two types high and low. Assume the planner is uncertain about the exact ability of these types but that the lowest possible high is known to be more able than the highest possible low. The planner can in effect pool all possible highs at the lowest possible values and similarly for the lows. The planner can then do the analysis here with the pooled types. There will be some loss in social welfare from the pooling but the planner can still do better than in the standard Mirrlees-Stiglitz analysis.

Finally, although we have focused on the optimal income taxation problem, there are important lessons from this analysis for any mechanism design problem with a finite number of agents. If only to avoid imposing infeasible actions off-the equilibrium path, policies affecting one agent cannot be independent of what other agents do. When such dependence occurs, then it becomes significant how agents reveal their attributes, by announcement or by action. The principle may be able to alter policies from ones initially announced. If so, the restrictions of partial commitment we considered here may be an appropriate and realistic possibility between assumptions of complete commitment and no commitment. 
${ }^{1}$ This issue of whether a budget surplus can simply be thrown away is an issue in Groves [1973]Clarke [1971] mechanisms which can be set up to run a surplus, but cannot be set up to balance the budget without losing the dominant strategy property. The Groves-Ledyard [1975] mechanism satisfies budget balance, but at the cost that truthful revelation is only a Nash equilibrium. In both of these analyses, the main focus is equilibrium budget balance and not offequilibrium properties, although Groves-Ledyard balances the budget in both circumstances.

${ }^{2}$ In an infinite-horizon dynamic model, Roberts [1984] showed that no redistribution would be possible. Any individual who reported that she was of the more able type would be forced to pay a large lump-sum tax every period after the report. There is no way the government could transfer enough resources to the individual in the initial period to make an individual willing to report that she is of the more able type. We discuss a one-period analogue of this result below.

${ }^{3}$ An alternative mechanism for this weak commitment would be that individuals report their types to an auditor who in turn reports aggregate information about the distribution of types. When the government uses this information to update its allocation, the auditor releases its knowledge about individual reports of types to the government only if those individuals who reported truthfully are not made worse off than they would be under the original announcements.

${ }^{4}$ Of course, when there is "noise" in the structure of the problem (for example, if the planner does not know the precise distribution of types), then any outcome may be on the equilibrium path with positive probability, and the distinction between on- and off-the-equilibrium path restrictions disappears.

${ }^{5}$ If the utility possibility frontier is not convex, some points on the UPF will not be solutions to this problem, but the first-order conditions will characterize these allocations. See Dorfman [1975, 1976] and Panzar and Willig [1976].

It is simpler not to write a general Bergson-Samuelson SWF, $\mathrm{W}\left(\mathrm{U}^{1}, \mathrm{U}^{2}\right)$, since the number of individuals of type may vary with individuals' reports. Were we to use such an SWF, an increase in the parameter $\alpha$ corresponds to an increase in the weight placed on type 1's utility relative to type 2's utility.

${ }^{6}$ In the action revelation game, the planner cannot sustain any allocation where $\mathrm{X}_{1}^{1}\left(\mathrm{n}_{1}, \alpha\right)=\mathrm{X}_{1}^{2}\left(\mathrm{n}_{1}, \alpha\right)$, that is where both types earn the same amount in the first-best allocation with truthful revelation. As long as leisure is strictly increasing in lump-sum income when $X_{1}>0$, this occurs only for a single value of $\alpha$. Since the planner could sustain the firstbest allocation for a value of $\alpha$ arbitrarily close to this value, we ignore this case in our formal analysis. Note that this issue only arises for transfers toward type 2, given normality of leisure.

${ }^{7}$ To understand the difference between (2) and (3), note that $\mathrm{U}^{1}\left(\mathrm{X}^{1}\left(\mathrm{~N}^{1}+1\right)\right) \geq \mathrm{U}^{1}\left(\mathrm{X}^{2}\left(\mathrm{~N}^{1}\right)\right), \mathrm{n}^{1} \leqq \mathrm{~N}^{1} \leqq \mathrm{n}^{1}+\mathrm{n}^{2}-1$, is required in (2) but not (3) while $\mathrm{U}^{2}\left(\mathrm{X}^{2}\left(\mathrm{~N}^{1}\right)\right) \geq \mathrm{U}^{2}\left(\mathrm{X}^{1}\left(\mathrm{~N}^{1}+1\right)\right), 0 \leq \mathrm{N}^{1} \leq \mathrm{n}^{1}-1$, must hold in (3) but not (2). In order to 
sustain the first best, $\mathrm{U}^{1}\left(\mathrm{X}^{1}\left(\mathrm{n}^{1}+1\right)\right) \geq \mathrm{U}^{1}\left(\mathrm{X}^{2}\left(\mathrm{n}^{1}, \alpha\right)\right)$ would be required for (2) but not (3) while $\mathrm{U}^{2}\left(\mathrm{X}^{2}\left(\mathrm{n}^{1}-1\right)\right) \geq \mathrm{U}^{2}\left(\mathrm{X}^{1}\left(\mathrm{n}^{1}, \alpha\right)\right)$ is needed for (3) but not (2). When redistribution is from 2 s to $1 \mathrm{~s}$ at the first best $\left(\mathrm{p} \cdot \mathrm{X}^{1}\left(\mathrm{n}^{1}, \alpha\right)>0\right.$ and $\left.\mathrm{p} \cdot \mathrm{X}^{2}\left(\mathrm{n}^{1}, \alpha\right)<0\right)$ then the former, especially when off-equilibrium budget balance is imposed, is less restrictive than the latter. On the other hand, if the direction of redistribution is reversed, then the above condition that is in (3) only is less restrictive than that in (2) only.

${ }^{8}$ In the Stiglitz [1982] model with a continuum of individuals, these two approaches are essentially equivalent, except that action revelation prevents randomization of both comsumption and earned income.

${ }^{9}$ Piketty actually shows this when more than two types exist.

${ }^{10}$ Information sets are specified by the value of $\mathrm{N}^{1}$. Any nonboundary value, $0<\mathrm{N}^{1}<\mathrm{n}$, can arise from multiple patterns of revelation. For example, with two individuals, $\mathrm{N}^{1}=1$ can arise either from both individuals telling the truth or both lying. Therefore, such nonboundary values do not define proper subgames. The equilibrium notion of subgame perfection is therefore too weak. The stronger notion of sequential equilibrium is needed. The planner believing that any value of $\mathrm{N}^{1}$ is achieved by the minimal number of deviations from truthful revelation is consistent with the beliefs specified by sequential equilibrium. 


\section{Appendix}

\section{Proof of Theorem 1:}

First, consider $\alpha$ such that no redistribution is done or redistribution is from type 2 s to type 1s. Then, the bundle $X^{2}\left(n^{1}, \alpha\right)$ lies on or below the line $p \cdot X=0$. Consider the following allocations to each type as a function of $\mathrm{N}^{1}$ :

$$
\begin{aligned}
& \text { For } N^{1}<n^{1}+1, \quad X^{1}\left(N^{1}\right)=X^{1}\left(n^{1}, \alpha\right) \\
& \qquad \begin{array}{l}
X^{2}\left(N^{1}\right) \text { solves } \underset{X^{2}}{\operatorname{Max}} U^{2}\left(X^{2}\right), \text { s.t. }\left(n-N^{1}\right) p \cdot X^{2}=-N^{1} p \cdot X^{1}\left(n^{1}, \alpha\right) \\
\text { For } N^{1}=n^{1}+1, X^{1}\left(n^{1}+1\right) \text { satisfies } p \cdot X^{1}\left(n^{1}+1\right)=0, U^{1}\left(X^{1}\left(n^{1}+1\right)\right)>U^{1}\left(X^{2}\left(n^{1}, \alpha\right)\right) \\
\quad \text { and } U^{2}\left(X^{1}\left(n^{1}+1\right)\right)<U^{2}\left(X^{2}\left(n^{1}, \alpha\right)\right) \\
X^{2}\left(n^{1}+1\right) \text { solves } \underset{X^{2}}{\operatorname{Max} U^{2}\left(X^{2}\right), ~ s . t . ~} p \cdot X^{2}=0
\end{array}
\end{aligned}
$$

For $\mathrm{N}^{1}>\mathrm{n}^{1}+1, \mathrm{X}^{1}\left(\mathrm{~N}^{1}\right)$ solves $\underset{\mathrm{X}^{1}}{\operatorname{Max}} \mathrm{U}^{1}\left(\mathrm{X}^{1}\right)$, s.t. $\mathrm{p} \cdot \mathrm{X}^{1}=0$

$$
\mathrm{X}^{2}\left(\mathrm{~N}^{1}\right) \text { solves } \underset{\mathrm{X}^{2}}{\operatorname{Max}} \mathrm{U}^{2}\left(\mathrm{X}^{2}\right) \text {, s.t. } \mathrm{p} \cdot \mathrm{X}^{2}=0
$$

By construction, budget balance is satisfied for all $\mathrm{N}^{1}$ and, for $\mathrm{N}^{1}=\mathrm{n}^{1}$, the allocations are the first best bundles $X^{1}\left(n^{1}, \alpha\right)$ and $X^{2}\left(n^{1}, \alpha\right)$. That a bundle $X^{1}\left(n^{1}+1\right)$ exists which satisfies the requirements given for it, follows from the assumptions on preferences. The bundle $X^{2}\left(n^{1}, \alpha\right)$ satisfies $\mathrm{p} \cdot \mathrm{X}^{2}\left(\mathrm{n}^{1}, \alpha\right)<0$. The indifference curves of both types through $\mathrm{X}^{2}\left(\mathrm{n}^{1}, \alpha\right)$ must intersect the line $\mathrm{p} \cdot \mathrm{X}=0$. From the single crossing assumption, the type 1 indifference curve intersects $\mathrm{p} \cdot \mathrm{X}=0$ closer to the origin than does the type 2 indifference curve. Any bundle on 
$p \cdot X=0$ between the two indifference curves that go through $X^{2}\left(n^{1}, \alpha\right)$ satisfies the requirements for $\mathrm{X}^{1}\left(\mathrm{n}^{1}+1\right)$.

To complete the proof for this case, dominance solvability must be shown.

Consider a single type 1 individual and let $\hat{\mathrm{N}}^{1}$ be the number of other individuals who have revealed themselves as type $1 \mathrm{~s}$. For any $\hat{\mathrm{N}}^{1}$ not equal to $\mathrm{n}^{1}$, the type 1 , by revealing truthfully, would get a bundle on some budget line $\mathrm{p} \cdot \mathrm{X}=\mathrm{K} \geq 0$, which is best on that line for type $1 \mathrm{~s}$. By misrevealing, the type 1 individual would get a bundle on a budget line $\mathrm{p} \cdot \mathrm{X}=\mathrm{C}$, some $\mathrm{C} \leq 0$, which is best on that line for type $2 \mathrm{~s}$. Clearly, the bundle under truthful revelation is strictly better than under misrevelation. If $\hat{\mathrm{N}}^{1}=\mathrm{n}^{1}$, then by construction, the bundle under truthful revelation $\left(X^{1}\left(n^{1}+1\right)\right)$ is superior to that under misrevelation $\left(X^{2}\left(n^{1}, \alpha\right)\right)$. Hence, (2a) is satisfied and revealing truthfully is a dominant strategy for any type 1.

Next, consider any type 2 . Given that all 1 s tell the truth, a type 2 will only face $\hat{\mathrm{N}}^{1} \geqq \mathrm{n}^{1}$. For $\hat{\mathrm{N}}^{1}>\mathrm{n}^{1}$, by telling the truth, the type 2 gets the best type 2 bundle on the line $\mathrm{p} \cdot \mathrm{X}=0$ while by misrevealing the type 2 individual gets the best type 1 bundle on that line. Clearly, the type 2 is better off being truthful. For $\hat{N}^{1}=n^{1}$, the type 2 if truthful gets $X^{2}\left(n^{1}, \alpha\right)$ while if misrevealing, gets $X^{1}\left(n^{1}+1\right)$ which is worse by construction. Hence, $(2 b)$ is satisfied and dominance solvability is shown.

Second, consider $\alpha$ such that redistribution is from type $1 \mathrm{~s}$ to type $2 \mathrm{~s}$. Now the bundle $\mathrm{X}^{1}\left(\mathrm{n}^{1}, \alpha\right)$ satisfies $\mathrm{p} \cdot \mathrm{X}^{1}\left(\mathrm{n}^{1}, \alpha\right)<0$. Consider the following allocations as functions of $\mathrm{N}^{1}$ :

$$
\text { For } \mathrm{N}^{1}<\mathrm{n}^{1}-1, \mathrm{X}^{1}\left(\mathrm{~N}^{1}\right) \text { solves } \underset{\mathrm{X}^{1}}{\operatorname{Max}} \mathrm{U}^{1}\left(\mathrm{X}^{1}\right) \text {, s.t. } \mathrm{p} \cdot \mathrm{X}^{1}=0
$$




$$
\mathrm{X}^{2}\left(\mathrm{~N}^{1}\right) \text { solves } \underset{\mathrm{X}^{2}}{\operatorname{Max}} \mathrm{U}^{2}\left(\mathrm{X}^{2}\right) \text {, s.t. } \mathrm{p} \cdot \mathrm{X}^{2}=0
$$

For $\mathrm{N}^{1}=\mathrm{n}^{1}-1, \mathrm{X}^{1}\left(\mathrm{n}^{1}-1\right)$ solves $\underset{\mathrm{X}^{1}}{\operatorname{Max}} \mathrm{U}^{1}\left(\mathrm{X}^{1}\right)$, s.t. $\mathrm{p} \cdot \mathrm{X}^{1}=0$

$$
\begin{gathered}
X^{2}\left(n^{1}-1\right) \text { satisfies } p \cdot X^{2}\left(n^{1}-1\right)=0, U^{1}\left(X^{1}\left(n^{1}, \alpha\right)\right)>U^{1}\left(X^{2}\left(n^{1}-1\right)\right), \\
\text { and } U^{2}\left(X^{2}\left(n^{1}-1\right)\right)>U^{2}\left(X^{1}\left(n^{1}, \alpha\right)\right)
\end{gathered}
$$

For $\mathrm{N}^{1}>\mathrm{n}^{1}-1, \mathrm{X}^{1}\left(\mathrm{~N}^{1}\right)$ solves $\underset{\mathrm{X}^{1}}{\operatorname{Max}} \mathrm{U}^{1}\left(\mathrm{X}^{1}\right)$, s.t. $\mathrm{N}^{1} \mathrm{p} \cdot \mathrm{X}^{1}=-\left(\mathrm{n}-\mathrm{N}^{1}\right) \mathrm{p} \cdot \mathrm{X}^{2}\left(\mathrm{n}^{1}, \alpha\right)$

$$
\mathrm{X}^{2}\left(\mathrm{~N}^{1}\right)=\mathrm{X}^{2}\left(\mathrm{n}^{1}, \alpha\right)
$$

The argument proceeds as in the previous case except (3) is shown instead of (2). The existence of a bundle $X^{2}\left(n^{1}-1\right)$ satisfying its requirements follows from the assumptions on preferences as income for a type approaches its upper bound.

Proof of Theorem 2: (A) At $\alpha^{0}$ no redistribution occurs. Bundles $X^{1}\left(1, \alpha^{0}\right)$ and $X^{2}\left(1, \alpha^{0}\right)$ are the tangency points of the respective type's indifference curves to the line $p \cdot X=0$. From single crossing, $X^{1}\left(1, \alpha^{0}\right) \neq X^{2}\left(1, \alpha^{0}\right)$. At $X_{1}^{1}(1, \alpha)$, type 1's indifference curve through $X^{2}\left(1, \alpha^{0}\right)$ is strictly below the $\mathrm{p} \cdot \mathrm{X}=0$ line and type 2 's indifference curve through $\mathrm{X}^{2}\left(1, \alpha^{\circ}\right)$ is strictly above that line. Hence $X_{2}(2)=X_{2}^{1}\left(1, \alpha^{\circ}\right)$ balances the budget and satisfies ( $\left.5 b\right)$ and $(5 c)$. For $\alpha$ near $\alpha^{\circ}$, the relation of the indifference curves to the $\mathrm{p} \cdot \mathrm{X}=0$ line will remain the same and budget balance will be possible.

(B) As $\alpha$ rises, $\mathrm{U}^{2}(\alpha) \equiv \mathrm{U}^{2}\left(\mathrm{X}^{2}(1, \alpha)\right)$ declines. For any $\mathrm{X}_{1}^{2}$, denote as $\mathrm{X}_{2}^{2}\left(\mathrm{X}_{1}^{2}, \mathrm{U}^{2}(\alpha)\right)$ the consumption $\mathrm{X}_{2}^{2}$ that is needed to reach $\mathrm{U}^{2}(\alpha)$. This consumption level declines to zero as $\alpha$ increases. Let $\hat{X}_{1}^{1}$ be the infimum over $\alpha$ of $X_{1}^{1}(1, \alpha)$, which by assumption is greater than zero. 
For sufficient redistribution from 2 to $1, \mathrm{X}_{2}^{2}\left(\hat{\mathrm{X}}_{1}^{1}, \mathrm{U}^{2}(\alpha)\right)<\hat{\mathrm{X}}_{1}^{1}$. Then, for all $\mathrm{X}_{1}^{1}$, with $\hat{X}_{1}^{1}<X_{1}^{1}<X_{1}^{2}(1, \alpha)$ (which includes $\left.X_{1}^{1}=X_{1}^{1}(1, \alpha)\right), X_{2}^{2}\left(X_{1}^{1}, U^{2}(\alpha)\right)<X_{1}^{1}$ must hold. Hence, a surplus is needed to sustain the first best allocation.

(C) To sustain $\mathrm{X}^{1}(1, \alpha)$ and $\mathrm{X}^{2}(1, \alpha)$ when $\mathrm{X}_{1}^{1}(1, \alpha)=0$ requires $\mathrm{X}_{1}(2)=0$ and $\mathrm{U}^{1}(\mathrm{X}(2))>$ $\mathrm{U}^{1}\left(\mathrm{X}^{2}(1, \alpha)\right)$. From the assumptions on preferences, $\mathrm{X}_{2}(2)>0$, thus a deficit occurs when both report they are type 1.

QED

Proof of Theorem 3: (A) If an off-equilibrium-path deficit is needed to sustain the first best allocation, then the planner's optimization problem reduces to:

$$
\begin{aligned}
& \operatorname{Max} \quad \alpha U^{1}\left(X_{1}^{1}, X_{2}^{1}\right)+(1-\alpha) U^{2}\left(X_{1}^{2}, X_{2}^{2}\right) \\
& \mathrm{X}_{1}^{1}, \mathrm{X}_{2}^{1}, \mathrm{X}_{1}^{2}, \mathrm{X}_{2}^{2} \\
& \text { s.t. } \quad X_{1}^{1}-X_{2}^{1}+X_{1}^{2}-X_{2}^{2} \geq 0: \mu \\
& \mathrm{U}^{1}\left(\mathrm{X}_{1}^{1}, \mathrm{X}_{1}^{1}\right) \geq \mathrm{U}^{1}\left(\mathrm{X}_{1}^{2}, \mathrm{X}_{2}^{2}\right): \lambda
\end{aligned}
$$

where the only incentive constraint needed is $(5 b)$ with $X_{1}^{1}=X_{2}^{1}$ implied by budget balance. The first order conditions reduce to:

$$
\begin{aligned}
& \alpha\left[U_{1}^{1}\left(X_{1}^{1}, X_{2}^{1}\right)+U_{2}^{1}\left(X_{1}^{1}, X_{2}^{1}\right)\right]=-\lambda\left[U_{1}^{1}\left(X_{1}^{1}, X_{1}^{1}\right)+U_{2}^{1}\left(X_{1}^{1}, X_{1}^{1}\right)\right] \\
& (1-\alpha)\left[U_{1}^{2}\left(X_{1}^{2}, X_{2}^{2}\right)+U_{2}^{2}\left(X_{1}^{2}, X_{2}^{2}\right)\right]=\lambda\left[U_{1}^{1}\left(X_{1}^{2}, X_{2}^{2}\right)+U_{2}^{1}\left(X_{1}^{2}, X_{2}^{2}\right)\right] \\
& \alpha U_{2}^{1}\left(X_{1}^{1}, X_{2}^{1}\right)-(1-\alpha) U_{2}^{2}\left(X_{1}^{2}, X_{2}^{2}\right)=-\lambda U_{2}^{1}\left(X_{1}^{2}, X_{2}^{2}\right)
\end{aligned}
$$

From (A1a) and normality, $\mathrm{U}_{1}^{1}\left(\mathrm{X}_{1}^{1}, \mathrm{X}_{2}^{1}\right)+\mathrm{U}_{2}^{1}\left(\mathrm{X}_{1}^{1}, \mathrm{X}_{2}^{1}\right)<0<\mathrm{U}_{1}^{1}\left(\mathrm{X}_{1}^{1}, \mathrm{X}_{1}^{1}\right)+\mathrm{U}_{2}^{1}\left(\mathrm{X}_{1}^{1}, \mathrm{X}_{1}^{1}\right)$. Hence, $\operatorname{MRS}^{1}\left(\mathrm{X}_{1}^{1}, \mathrm{X}_{2}^{1}\right)>1$. This means that $\mathrm{X}_{1}^{1}$ is greater than the undistorted income on that $\mathrm{p} \cdot \mathrm{X}=\mathrm{K}$ line. Second, from (A2a), $\operatorname{MRS}^{1}\left(X_{1}^{2}, X_{2}^{2}\right)$ and $\operatorname{MRS}^{2}\left(X_{1}^{2}, X_{2}^{2}\right)$ must be of the same sign. From a bundle such that $\operatorname{MRS}^{1}\left(X_{1}^{2}, X_{2}^{2}\right)>\operatorname{MRS}^{2}\left(X_{1}^{2}, X_{2}^{2}\right)>1$, moving both the $X^{1}$ and $X^{2}$ bundles along 
their budget lines toward undistorted bundles would raise both 1's and 2's utility and continue to satisfy all constraints. Thus, an allocation with $\operatorname{MRS}^{1}\left(X_{1}^{2}, X_{2}^{2}\right)>\operatorname{MRS}^{2}\left(X_{1}^{2}, X_{2}^{2}\right)>1$ is subject to a Pareto improvement. Hence, $1>\operatorname{MRS}^{1}\left(\mathrm{X}_{1}^{2}, \mathrm{X}_{2}^{2}\right)>\operatorname{MRS}^{2}\left(\mathrm{X}_{1}^{2}, \mathrm{X}_{2}^{2}\right)$ must hold.

From (A1c) if $\mathrm{X}_{1}^{1}$ and $\mathrm{X}_{1}^{2}$ were fixed and the incentive constraint remained, $\mathrm{X}_{2}^{1}$ would be reduced and $X_{2}^{2}$ increased since $\alpha U_{2}^{1}\left(X_{1}^{1}, X_{2}^{1}\right)<(1-\alpha) U_{2}^{2}\left(X_{1}^{2}, X_{2}^{2}\right)$.

(B) If an off-equilibrium-path surplus is needed to sustain the first-best allocation, the planner's optimization problem now uses (5c) and becomes:

$$
\begin{array}{cc}
\operatorname{Max} & \alpha \mathrm{U}^{1}\left(\mathrm{X}_{1}^{1}, \mathrm{X}_{2}^{1}\right)+(1-\alpha) \mathrm{U}^{2}\left(\mathrm{X}_{1}^{2}, \mathrm{X}_{2}^{2}\right) \\
\mathrm{X}_{1}^{1}, \mathrm{X}_{2}^{1}, \mathrm{X}_{1}^{2}, \mathrm{X}_{2}^{2} & \\
\text { s.t. } & \mathrm{X}_{1}^{1}-\mathrm{X}_{2}^{1}+\mathrm{X}_{1}^{2}-\mathrm{X}_{2}^{2} \geq 0: \mu \\
& \mathrm{U}^{2}\left(\mathrm{X}_{1}^{2}, \mathrm{X}_{2}^{2}\right) \geq \mathrm{U}^{2}\left(\mathrm{X}_{1}^{1}, \mathrm{X}_{1}^{1}\right): \lambda
\end{array}
$$

The first order conditions reduce to:

$$
\begin{aligned}
& \alpha\left[\mathrm{U}_{1}^{1}\left(\mathrm{X}_{1}^{1}, \mathrm{X}_{2}^{1}\right)+\mathrm{U}_{2}^{1}\left(\mathrm{X}_{1}^{1}, \mathrm{X}_{2}^{1}\right)\right]=\lambda\left[\mathrm{U}_{1}^{1}\left(\mathrm{X}_{1}^{1}, \mathrm{X}_{1}^{1}\right)+\mathrm{U}_{2}^{1}\left(\mathrm{X}_{1}^{1}, \mathrm{X}_{1}^{1}\right)\right] \\
& {[1-\alpha+\lambda]\left[\mathrm{U}_{1}^{2}\left(\mathrm{X}_{1}^{2}, \mathrm{X}_{2}^{2}\right)+\mathrm{U}_{2}^{2}\left(\mathrm{X}_{1}^{2}, \mathrm{X}_{2}^{2}\right)\right]=0} \\
& \alpha \mathrm{U}_{2}^{1}\left(\mathrm{X}_{1}^{1}, \mathrm{X}_{2}^{1}\right)-(1-\alpha) \mathrm{U}_{2}^{2}\left(\mathrm{X}_{1}^{2}, \mathrm{X}_{2}^{2}\right)=\lambda \mathrm{U}_{2}^{2}\left(\mathrm{X}_{1}^{2}, \mathrm{X}_{2}^{2}\right)
\end{aligned}
$$

Since $U_{1}^{1}\left(X_{1}^{1}, X_{1}^{1}\right)+U_{2}^{1}\left(X_{1}^{1}, X_{1}^{1}\right)>0$ as in the proof of $(A)$ and $\lambda U_{2}^{2}>0$, the result in (B) follows immediately.

QED

Proof of Theorem 4: Consider the two person case and let $\bar{\alpha}$ be the social weight such that the maximum redistribution is being done toward type $1 \mathrm{~s}$ without the need to create any distortions. Denote $\mathrm{X}^{\mathrm{i}}(1, \bar{\alpha})$ as the first best bundles that would solve maximization problem (I) for $\alpha$ equal to $\bar{\alpha}$. Then the bundles $X^{i}(1)=X^{i}(1, \bar{\alpha}), X(2)=\left(X_{1}^{1}(1, \bar{\alpha}), X_{1}^{1}(1, \bar{\alpha})\right)$, and 
$\mathrm{X}(0)=\left(\mathrm{X}_{1}^{2}(1, \bar{\alpha}), \mathrm{X}_{1}^{2}(1, \bar{\alpha})\right)$ balance the budget for all states. They satisfy dominance

solvability and yield the maximum undistorted redistribution if $\mathrm{U}^{2}\left(\mathrm{X}^{2}(1, \bar{\alpha})\right)=\mathrm{U}^{2}(\mathrm{X}(2))$.

This situation is shown in Figure 4.

Now assume that there are $n^{1}=n^{2}=2$ individuals of each type. Assigning $X^{i}(1, \bar{\alpha})$ to each individual of type $i$ will still be a first best Pareto optimum in the larger economy. If it is to be implemented, then $X^{2}(2)$ must equal $X^{1}(1, \bar{\alpha})$. Consider the bundle $X(4)$ that is assigned when everyone asserts they are a type 1 . Due to action revelation, $X_{1}(4)$ must equal $X_{1}^{1}(1, \bar{\alpha})$ and then due to budget balance, $X_{2}(4)$ must also equal $X_{1}^{1}(1, \bar{\alpha})$. Hence, $X(4)$ must be the same as the bundle $\mathrm{X}(2)$ when there were only two individuals.

Consider a type 1 indifference curve through the bundle X (4). First, assume that this intersects the line $\mathrm{X}_{2}^{2}=\mathrm{X}_{2}^{2}(1, \bar{\alpha})$ below the $\mathrm{p} \cdot \mathrm{X}=0$ line. Denote the intersection point as point A. Since the dominance solvability constraints imply that $\mathrm{U}^{1}(\mathrm{X}(4)) \geq \mathrm{U}^{1}\left(\mathrm{X}^{2}(3)\right)$ and that $\mathrm{U}^{2}\left(\mathrm{X}^{2}(3)\right) \geq \mathrm{U}^{2}(\mathrm{X}(4))$, then $\mathrm{X}^{2}(3)$ must lie on the line segment between point $\mathrm{A}$ and $\mathrm{X}^{2}(1, \bar{\alpha})$. To balance the budget when $\mathrm{N}^{1}=3, \mathrm{X}^{1}(3)$ must be above $\mathrm{X}^{1}(4)$ on the line $\mathrm{X}_{1}^{1}=\mathrm{X}_{1}^{1}(1, \bar{\alpha})$. But then $\mathrm{U}^{2}\left(\mathrm{X}^{2}(3)\right)>\mathrm{U}^{2}(\mathrm{X}(4))=\mathrm{U}^{2}\left(\mathrm{X}^{2}(1, \bar{\alpha})\right)$ which violates the incentive constraint that $\mathrm{U}^{2}\left(\mathrm{X}^{2}(2)\right) \geq \mathrm{U}^{2}\left(\mathrm{X}^{1}(3)\right)$. Hence, in this situation, the bundles $\mathrm{X}^{2}(1, \bar{\alpha})$ cannot be implemented when there are two individuals of each type.

A second possibility is if the type 1 indifference curve through the bundle $X(4)$ intersects the line $\mathrm{X}_{2}^{2}=\mathrm{X}_{2}^{2}(1, \bar{\alpha})$ above the $\mathrm{p} \cdot \mathrm{X}=0$ line. Since the $\mathrm{X}^{2}$ (3) bundle can now be chosen so 
that $p \cdot X^{2}(3)>0$, then the $X^{1}(3)$ bundle will be below $X(4)$. This implies that $\mathrm{U}^{2}\left(\mathrm{X}^{2}(1, \bar{\alpha})\right)>\mathrm{U}^{2}\left(\mathrm{X}^{1}(3)\right)$. Not only is the allocation $\mathrm{X}^{\mathrm{i}}(1, \bar{\alpha})$ sustainable, but because the dominance solvability constraints all hold with strict inequality, it is actually possible to sustain allocations $\mathrm{X}^{\mathrm{i}}(1, \alpha)$ for at least some $\alpha$ greater than $\bar{\alpha}$. In this case, more undistorted allocations are implementable with four individuals than with two.

Proof of Theorem 5: In stage four of the game, for each $\mathrm{N}^{1}$, the budget must exactly balance under reoptimization. A deficit is infeasible and a surplus could be divided among the individuals raising the utilities of both types. Whatever outcome results under the constrained reoptimization must also have been feasible in the problem with just budget balance. Hence, the planner cannot do better with reoptimization. If the solution under just budget balance is also possible with reoptimization, then the outcomes must be equivalent. Take the solution to (IV), $\mathrm{X}^{\mathrm{i}}\left(\mathrm{N}^{1}\right)$, all $\mathrm{N}^{1}$. Assume that these vectors form the planner's initial announcements. Any change in these by reoptimization can only be in the consumption vectors since incomes are fixed. Budget balance implies that, if any type's consumption is increased at any $\mathrm{N}^{1}$, then the other type's consumption must be lowered. This would violate partial commitment since for each $\mathrm{N}^{1}$ the equilibrium belief is that at least some people who revealed themselves to be each type are truthful and their welfare cannot be reduced.

QED

Proof of Theorem 6: By assumption $\alpha(2) \geq \alpha$. Consider the no-redistribution $\alpha^{0}>0$. The bundle selected by social preferences defined by $\alpha(2)$ must lie strictly between $X^{1}\left(1, \alpha^{o}\right)$ and $\mathrm{X}^{2}\left(1, \alpha^{\mathrm{o}}\right)$. Hence, $\mathrm{U}^{2}\left(\mathrm{X}^{2}\left(1, \alpha^{o}\right)\right)>\mathrm{U}^{2}(\hat{\mathrm{X}}(2))$. This will hold for some range of $\alpha$ near $\alpha^{\mathrm{o}}$ leading (7c) to be satisfied for all $\alpha$ in that range. Individuals will reveal truthfully and the first best will be implemented. The less weight the planner gives to the misrevealing individual, the more $\alpha(2)$ 
differs from $\alpha$ and the larger will be the range including $\alpha^{\circ}$ at which the first best can be achieved. Once $\alpha$ goes outside this range, the type 2 individual will misreveal and the planner then has no choice but to implement $\hat{X}(2)$.

For $\alpha<\alpha^{0}$, the issue is whether the type 1 individual will lie with a similar analysis based upon $\alpha(0)$.

QED

Proof of Theorem 7: Consider the announced policies for the planner in stage two: $\mathrm{X}(0)=$ $X^{2}\left(1, \alpha^{0}\right), X(2)=X^{1}\left(1, \alpha^{0}\right)$, and $X^{1}(1)=X^{1}(1, \alpha), X^{2}(1)=X^{2}(1, \alpha)$, for $\alpha \leq \bar{\alpha}$ and $X^{1}(1)=$ $\mathrm{X}^{1}(1, \bar{\alpha})$ and $\mathrm{X}^{2}(1)=\mathrm{X}^{2}(1, \bar{\alpha}), \alpha \geq \bar{\alpha}$. Under the entitlements of these policies, the planner will implement these in each circumstance in stage four, and in stage three, truth telling is the dominance solvable equilibrium. Hence, under these announcements, $X^{1}(1)$ and $X^{2}(1)$ are the subsequent equilibrium outcomes. The planner cannot do better by other announcements in stage 2. For $\alpha \leq \bar{\alpha}$, the outcome is first-best, so it cannot be improved upon. For $\alpha>\hat{\alpha}$, if some other announced policies were to lead to $\mathrm{U}^{2}\left(\mathrm{X}^{2}(1)\right)<\mathrm{U}^{2}\left(\mathrm{X}^{2}(1, \bar{\alpha})\right)$, then type 2 would misreveal, yielding an outcome $\mathrm{U}^{1}(\hat{\mathrm{X}}(2))$ and $\mathrm{U}^{2}(\hat{\mathrm{X}}(2))$, some $\hat{\mathrm{X}}(2)$ with $\mathrm{X}^{1}\left(1, \alpha^{0}\right) \leq \hat{\mathrm{X}}(2) \leq \mathrm{X}^{2}\left(1, \alpha^{0}\right)$. This is Pareto dominated by the no-redistribution utilities $\mathrm{U}^{1}\left(\mathrm{X}^{1}\left(1, \alpha^{0}\right)\right)$ and $\mathrm{U}^{2}\left(\mathrm{X}^{2}\left(1, \alpha^{0}\right)\right)$ which in turn are worse for the planner than $\mathrm{U}^{1}\left(\mathrm{X}^{1}(1, \bar{\alpha})\right)$ and $\mathrm{U}^{2}\left(\mathrm{X}^{2}(1, \bar{\alpha})\right)$ given any $\alpha>\bar{\alpha}$, since the planner desires even more redistribution than occurs for $\bar{\alpha}$. If other stage two announcements led to $\mathrm{U}^{2}\left(\mathrm{X}^{2}(1)\right)>\mathrm{U}^{2}\left(\mathrm{X}^{2}(1, \bar{\alpha})\right)$, then less redistribution would be done than at $X^{1}(1, \bar{\alpha})$ and $X^{2}(1, \bar{\alpha})$ and would be socially inferior. Hence no other announcements in stage two can improve welfare. Thus, these outcomes are the unique equilibrium of the game. 
Since $\mathrm{U}^{2}\left(\mathrm{X}^{1}\left(1, \alpha^{0}\right)\right)<\mathrm{U}^{2}(\hat{\mathrm{X}}(2))$, for $\hat{\mathrm{X}}(2)$ maximizing $\alpha(2) \mathrm{U}^{1}(\hat{\mathrm{X}}(2))+$ $(1-\alpha(2)) \mathrm{U}^{2}(\hat{\mathrm{X}}(2))$ subject to $\mathrm{p} \cdot \hat{\mathrm{X}}(2)=0,(8 \mathrm{c})$ is a looser constraint than (7c), so at $\alpha=\bar{\alpha}$, where (8c) just binds, (7c) is strictly violated. This shows that under partial commitment more of the first-best utility possibility frontier is achievable than with no commitment. Likewise, in problem (II), for $\alpha$ for which the solution is on the utility possibility frontier, $\mathrm{U}^{2}\left(\mathrm{X}^{2}(1, \alpha)\right) \geq$ $\mathrm{U}^{2}\left(\mathrm{X}^{1}(1, \alpha)\right)$. This is also a tighter constraint than $(8 \mathrm{c})$ since $\mathrm{U}^{2}\left(\mathrm{X}^{1}(1, \alpha)\right)>\mathrm{U}^{2}\left(\mathrm{X}^{1}\left(1, \alpha^{0}\right)\right)$, $\alpha>\alpha^{\circ}$.

Under action revelation, sometimes the entire first-best frontier can be achieved whereas under announcement revelation, the achievable first-best frontier is always truncated. Thus, sometimes the outcome is better under action revelation. On the other hand, at $\bar{\alpha}$, it is possible that type 1's indifference curve through $X^{2}(1, \bar{\alpha})$ will lie above the $p \cdot X=0$ line at $X_{1}^{1}(1, \bar{\alpha})$. Hence, the outcome will be off the first-best frontier under action revelation but on it under announcement revelation.

Proof of Theorem 8: Consider the case where $n^{1}=n^{2}=2$. If we restrict attention to those points on the full information utility possibility frontier, at which individuals of the same type are treated equally, then the utility possibility frontier is the same as when $n^{1}=n^{2}=1$. As before, we consider $\alpha>\alpha^{0}$ so redistribution is toward type $1 \mathrm{~s}$. Therefore, the dominance-solvability conditions are those in which type $1 \mathrm{~s}$ always tell the truth and type $2 \mathrm{~s}$ tell the truth if type $1 \mathrm{~s}$ do. There are five possible information sets, $\mathrm{N}^{1}=0,1,2,3$, or 4 . Denote the equilibrium allocation to be sustained as $X^{1}(2, \alpha)$ and $X^{2}(2, \alpha)$. The planner must then choose utility guarantees such that the off-equilibrium-path allocations satisfy the following dominance solvability constraints $\alpha$ which reduce to: 


$$
\begin{aligned}
& \mathrm{U}^{1}\left(\mathrm{X}^{1}(4)\right) \geq \mathrm{U}^{1}\left(\mathrm{X}^{2}(3)\right) \\
& \mathrm{U}^{1}\left(\mathrm{X}^{1}(3)\right) \geq \mathrm{U}^{1}\left(\mathrm{X}^{2}(2, \alpha)\right) \\
& \mathrm{U}^{1}\left(\mathrm{X}^{1}(2, \alpha)\right) \geq \mathrm{U}^{1}\left(\mathrm{X}^{2}(1)\right) \\
& \mathrm{U}^{1}\left(\mathrm{X}^{1}(1)\right) \geq \mathrm{U}^{1}\left(\mathrm{X}^{2}(0)\right) \\
& \mathrm{U}^{2}\left(\mathrm{X}^{2}(2, \alpha)\right) \geq \mathrm{U}^{2}\left(\mathrm{X}^{1}(3)\right) \\
& \mathrm{U}^{2}\left(\mathrm{X}^{2}(3)\right) \geq \mathrm{U}^{2}\left(\mathrm{X}^{1}(4)\right)
\end{aligned}
$$

Note that, unlike when $n^{1}=n^{2}=1$, the planner's choice of $X^{1}(3)$ is not constrained to lie on the no-redistribution budget line. Committing to a utility guarantee $\mathrm{U}^{2}\left(\mathrm{X}^{2}(3)\right)>\mathrm{U}^{2}\left(2, \alpha_{0}\right)$ makes it credible for the planner to choose $\mathrm{X}^{1}(3)$ below the no-redistribution line, which allows the planner to reduce $\mathrm{U}^{2}\left(\mathrm{X}^{2}(2, \alpha)\right)$. As with the $\mathrm{X}^{1}(2)$ bundle with a single consumer of each type, offering efficient bundles (on the $\mathrm{MRS}^{\mathrm{i}}=1$ locus) allows the planner to discourage misreporting as much as possible among all bundles on a given budget line (given the credibility restrictions from the reoptimization).

The bundles $X^{1}(3), X^{1}(4)$, and $X^{2}(3)$ each appear on the LHS and RHS of different inequalities. Since $\mathrm{X}^{1}(4)$ must lie on the no-redistribution line, the incentive constraints (A3a), $(\mathrm{A} 3 \mathrm{~b})$, and $(\mathrm{A} 3 \mathrm{f})$ and the budget constraint $\mathrm{p} \cdot\left[3 \mathrm{X}^{1}(3)+\mathrm{X}^{2}(3)\right]=0$ may restrict the set of efficient allocations the planner can achieve. Observe that the set of efficient allocations the planner can sustain is greater than when there is only one consumer of each type. In Figure 5, by choosing the maximum $X^{2}(3)$ given (A3a), the planner can commit to a low level for $U^{2}\left(X^{1}(3)\right)$, allowing more redistribution from type 2 to type 1 under truthful reporting.

Figure 6 displays the set of utility guarantees and off-equilibrium-path bundles to sustain the maximum transfer from type 2 to type 1 when $n^{1}=n^{2}=4$. Observe that the utility guarantees 
to truthful type 2's involve redistribution both toward and away from that group. The bundle $\mathrm{X}^{2}(5)$ is constructed to be as costly as possible to make it credible that $\mathrm{U}^{2}\left(\mathrm{X}^{1}(5)\right)$ is so low. Any first-best allocation with $\left.\mathrm{U}^{2}\left(4, \alpha^{0}\right)\right)>\mathrm{U}^{2}>\mathrm{U}^{2}\left(\mathrm{X}^{2}(4, \alpha)\right)$ can be implemented as a dominancesolvable equilibrium. Given this, the maximal transfer when $n^{1}=n^{2}=2$ is less than the maximal transfer when $n^{1}=n^{2}=4$. Note that $X^{2}(7)$ in Figure 6 is the same as $X^{2}(3)$ in Figure 5. Let $D$ be the value of the transfer to truthful type 2's in the $\mathrm{X}^{2}(7)$ bundle, and let $\mathrm{E}$ be the value of the tax on those reporting to be type 1's in the $\mathrm{X}^{1}(7)$ bundle. The amount $\mathrm{D}$ is fixed by the point where type 1's indifference curve which is tangent to the no-redistribution line intersects the locus of allocations where $\mathrm{MRS}^{2}=1$ (the efficient bundles to give type 2); it is independent of $n^{1}, \mathrm{n}^{2}$ and the number of misreporting agents. From budget balance, for $n^{1}=n^{2}=2,3 E=D$. With $n^{1}=n^{2}$ $=4, E^{\prime}$ is the maximum net tax that can be extracted from type 1 reporters when only one type 2 misreports. From budget balance, $5 \mathrm{E}^{\prime}=3 \mathrm{D}^{\prime}$. Since $\mathrm{D}^{\prime}>\mathrm{D}, \mathrm{E}^{\prime}>\mathrm{E}$ and, thus, in equilibrium under truthful revelation, type 2's can be made worse off when $n^{1}=n^{2}=4$ than when $n^{1}=n^{2}=2$. (This holds as well for the case of $n^{1}=n^{2}=3$.)

When $n^{1}=n^{2}>4$, let the no-redistribution efficient bundles be $\mathrm{X}^{1}\left(\mathrm{~N}^{1}\right)$ and $\mathrm{X}^{2}\left(\mathrm{~N}^{1}\right)$ for all $N^{1} \geq n^{1}+4$. Then let $X^{2}\left(n^{1}+3\right)$ be the same bundle as $X^{2}(7)$ when $n^{1}=n^{2}=4$. Let $\bar{E}$ be the value of the net tax paid by type 1 's when $\mathrm{N}^{1}=\mathrm{n}^{1}+3, \overline{\mathrm{F}}$ be the net tax paid by type 2 's when $\mathrm{N}^{1}=\mathrm{n}^{2}+2, \overline{\mathrm{F}}^{\prime}$ be the net transfer to type 1's when $\mathrm{N}^{1}=\mathrm{n}+2, \overline{\mathrm{D}}^{\prime}$ be the net transfer to type 2's when $N^{1}=n^{1}+1$ and $E^{\prime}$ be the net tax paid by type 1 's when $N^{1}=n^{1}+1$. D is the same when $n^{1}$ $=4$ and $n^{1}>4$. Since $3 E=D$ and $\left(n^{1}+3\right) \bar{E}=\left(n^{1}-3\right) D, \bar{E}>E$, thus $\bar{F}>F$ since 2 's indifference curve through $X^{1}\left(n^{1}+3\right)$ is lower. Since $\bar{F}>F$ and $\left(n^{1}+2\right) \bar{F}^{\prime}=\left(n^{1}-2\right) \bar{F}, \bar{F}^{1}>F^{\prime}$ for $n^{1}>4$. 
Since $\overline{\mathrm{F}}^{\prime}>\mathrm{F}^{\prime}, \overline{\mathrm{D}}^{1}>\mathrm{D}^{1}$ since $\mathrm{X}^{2}\left(\mathrm{n}^{1}+1\right)$ is on a higher indifference curve for 2. Since $\left(n^{1}+1\right) \overline{\mathrm{E}}^{\prime}=\left(\mathrm{n}^{1}-1\right) \overline{\mathrm{D}}^{\prime}, \overline{\mathrm{E}}^{\prime}>\mathrm{E}^{\prime}$ follows.

Thus the planner can extract more resources from type 2 as $n^{1}$ and $n^{2}$ grow in proportion. QED 


\section{References}

Baron, D. and D. Besanko, 1987, Commitment and Fairness in a Dynamic Regulatory Relationship, Review of Economic Studies 54: 413-436.

Brito, D., J. Hamilton, S. Slutsky, and J. Stiglitz, 1990, Pareto Efficient Tax Schedules, Oxford Economic Papers 42: 61-77.

Clarke, E., 1971, Multipart Pricing of Public Goods, Public Choice 11: 17-33.

Dorfman, R., 1975, Note on a Common Mistake in Welfare Economics, Journal of Political Economy 83: 863-864.

Dorfman, R., 1976, Rejoinder, Journal of Political Economy 84: 1365-1366.

Farrell, J. and E. Maskin, 1989, Renegotiation in Repeated Games, Games and Economic Behavior 1: 327-360.

Fudenberg, D. and J. Tirole, 1990, Moral Hazard and Renegotiation in Agency Contracts, Econometrica 58: 1279-1319.

Groves, T., 1973, Incentives in Teams, Econometrica 41: 617-663.

Groves, T. and J. Ledyard, 1977, Optimal Allocation of Public Goods: A Solution to the "Free Rider" Problem, Econometrica 45: 783-809.

Hamilton, J. and S. Slutsky, 2002, Nonlinear Price Discrimination with a Finite Number of Consumers and Constrained Recontracting, Mimeo, University of Florida

Hammond, P., 1979, Straightforward Incentive Compatibility in Large Economies, Review of Economic Studies 46: 263-282.

Maskin, E. and J. Riley, 1984, Monopoly with Incomplete Information, RAND Journal of Economics 15: 171-196.

Mirrlees, J., 1971, An Exploration in the Theory of Optimal Income Taxation, Review of Economic Studies 38: 175-208.

Panzar, J., and R. Willig, 1976, Vindication of a "Common Mistake" in Welfare Economics, Journal of Political Economy 84: 1361-1363.

Piketty, T., 1993, Implementation of First-Best Allocations via Generalized Tax Schedules, Journal of Economic Theory 61: 23-41. 
Roberts, K., 1984, The Theoretical Limits of Redistribution, Review of Economic Studies 51:177-195.

Stiglitz, J., 1974, Monopoly, Non-linear Pricing and Imperfect Information: The Insurance Market, Review of Economic Studies 41: 407-430.

Stiglitz, J., 1982, Self-Selection and Pareto Efficient Taxation, Journal of Public Economics 17: 213-240.

Stiglitz, J., 1986, Pareto Efficient and Optimal Taxation and the New New Welfare Economics, in A. Auerbach and M. Feldstein, eds., Handbook of Public Economics, vol. 2, Amsterdam: North-Holland. 
